\title{
Total synthesis of the big four antibiotics and related antibiotics
}

\author{
Kuniaki Tatsuta \\ The first total syntheses of a variety of antibiotics have been accomplished by using carbohydrates as a chiral source. \\ The key target molecules were members of the 'Big Four' classes of antibiotics (macrolides, aminoglycosides, $\beta$-lactams \\ and tetracyclines), naphthoquinone antibiotics and their related antibiotics. \\ The Journal of Antibiotics (2013) 66, 107-129; doi:10.1038/ja.2012.126
}

Keywords: antibiotics; carbohydrates; enantiospecific synthesis; natural products; total synthesis

\section{INTRODUCTION}

'Antibiotic' was one of the greatest scientific discoveries in the 20th century and the masterpiece of the total synthesis of antibiotics and bioactive natural products is a display of beauty, achieving a status of 'art' in organic chemistry.

Anybody can draw a picture, but pictures painted by famous painters such as van Gogh, Monet and Picasso are praised as 'art'. At the present time, many chemists are able to synthesize natural products, even those having complicated structure, using advanced organic chemistry. However, not all such synthesis is above the mundane and can thus be raised to the level of 'art'. The author is of the opinion that 'art' is a sublimate of originality, and has inherent special characteristics, and, even in the 21 st century, it should be recognized as such.

Among bioactive natural products, several antibiotics, termed as the 'Big Four', were the foremost subject of research at the time the author started his study of antibiotic synthesis. ${ }^{1}$ As shown in Figure 1, they were the macrolides (oleandomycin (1), erythromycin A (2), leucomycin $\mathrm{A}_{3}$ (3), tylosin (4)), aminoglycosides (kanamycin A (5), apramycin (6)), $\beta$-lactams (thienamycin (7)) and tetracyclines (tetracycline (8)). The author's group has fortunately succeeded in completing the total syntheses of 102 diverse bioactive natural products, including the above-mentioned representatives of the big four antibiotics, and 95 of them represented the first total synthesis of the respective compounds. ${ }^{2-6}$ It is noteworthy that most of optically active compounds have been synthesized efficiently using carbohydrates as chiral sources, to help determine the absolute structure and to clarify their structure-activity relationships. The methodologies devised are now established as the usual way in the natural product synthesis. ${ }^{2-6}$

The first total synthesis requires the creation of original synthesis concepts and methodologies, including the definition of the absolute structure of the bioactive natural products, as well as the verification of their biological activities.
In the present paper, the author introduces the dynamic as well as elegant parts of his total synthesis of big four antibiotics and related compounds, focusing not only on 'art' but also on the significance of the total syntheses, and featuring his concept of 'all begins from total synthesis.

\section{TOTAL SYNTHESIS OF MACROLIDE ANTIBIOTICS AND THE RELATED MACROLACTONE ANTIBIOTICS}

When a stone is thrown into a pond, several ripples are produced in succession, gradually radiating outward from the point of entry until they finally cover the whole pond. The 'stone' in macrolide synthesis was the news that R B Woodward had begun the total synthesis of erythromycin A (2) in 1973. His group including the author accomplished the total synthesis in 1981. Some ripples from this point of origin are represented by Masamune's methymycin synthesis in 1977, Corey's erythronolide synthesis in 1978 and our syntheses of carbomycin B, leucomycin $A_{3}(3)$ and tylosin (4) in 1977 and 1981. ${ }^{1-6}$

The first total synthesis of 16-membered macrolide antibiotics The first total syntheses of the 16-membered macrolide antibiotics, A26771B (1980), ${ }^{7}$ carbomycin B (1980), ${ }^{8,9}$ leucomycin $\mathrm{A}_{3}$ (josamycin, 1980), ${ }^{8,9}$ and tylosin $(1982)^{10,11}$ were accomplished in our laboratories. ${ }^{1-6}$ These syntheses were based on the stereoselective construction of the carbon skeletons from D-glucose as shown in Figure 2.

The first total synthesis of tylosin (4) was accomplished by coupling of the C1-C10 (13) and C11-C15 (14) segments derived from D-glucose, and the stereo- and regio-selective introduction of the three sugar moieties (17, 19 and 22) (Figure 3). ${ }^{10,11}$ The C-methyl compound 9, derived from D-glucose, was converted into the unsaturated ester 10, which was transformed to the methyl ketone 13 through a Michael addition with lithiated methyl methylthiomethyl sulfoxide to give the branched ester 12. This 


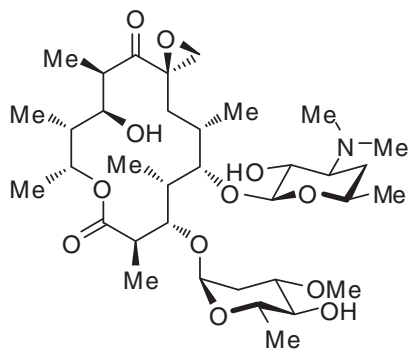

Oleandomycin (1)

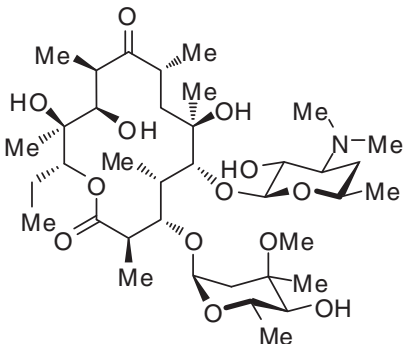

Erythromycin A (2)

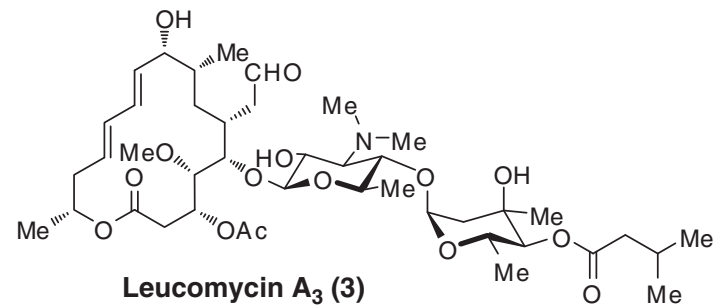

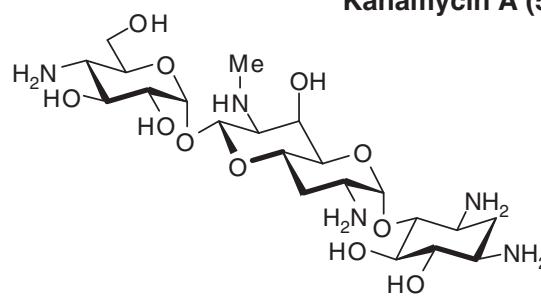

Apramycin (6) Aminoglycoside Antibiotics

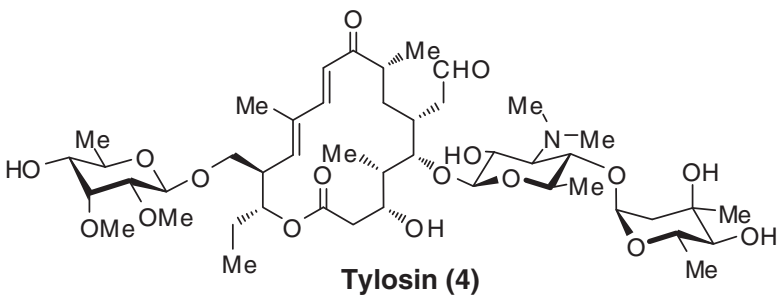

Tylosin (4)<smiles>CC(O)C1C(=O)N2C(C(=O)O)=C(SCCN)C[C@H]12</smiles>

Thienamycin (7)

Macrolide Antibiotics

$\beta$-Lactam Antibiotic<smiles>CN(C)[C@@H]1C(O)=C(C(N)=O)C(=O)[C@@]2(O)C(O)=C3C(=O)c4c(O)cccc4[C@@](C)(O)[C@@H]3C[C@H]12</smiles>

Tetracycline (8)

Tetracycline Antibiotic

Figure 1 Representatives of big four antibiotics.

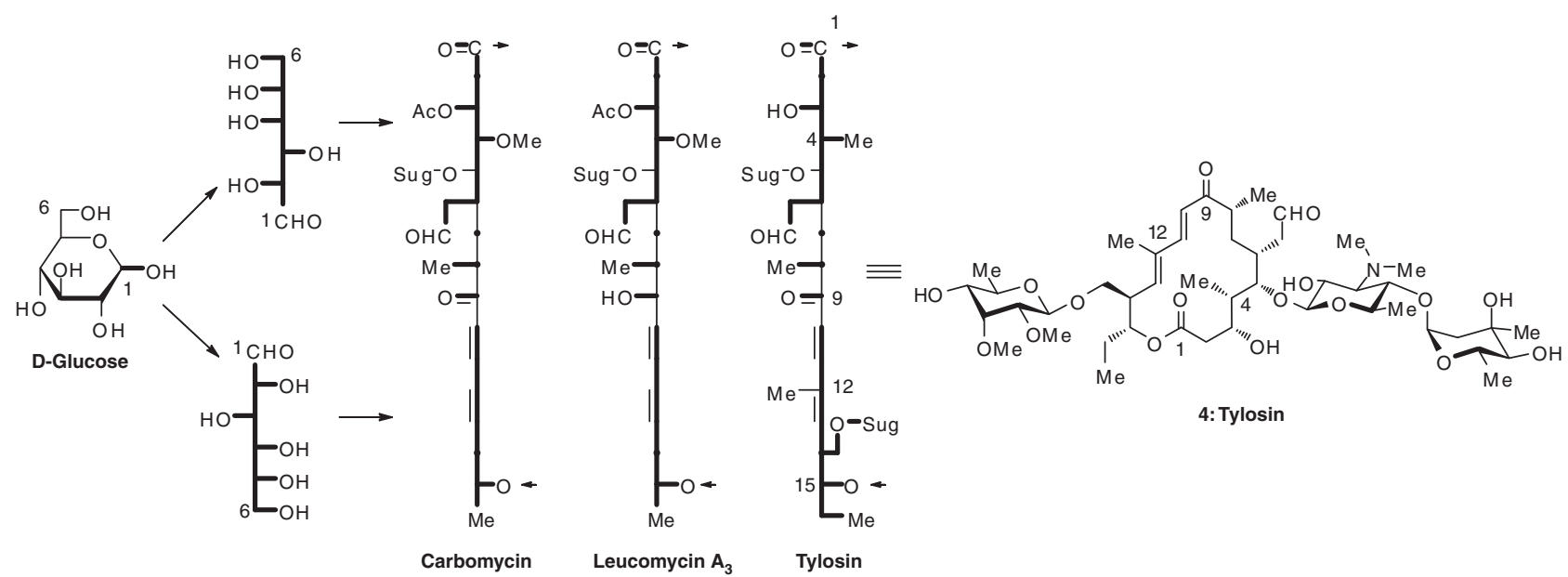

Figure 2 Total synthesis of 16-membered macrolide antibiotics from D-glucose.

addition of the lithiated reagent to the correct position from the desired side was effectively assisted by the metal chelation between the isopropylidene oxygen and the carboxyl oxygen of the transition state 11, to give only the natural configuration at C6, as expected. This step was the first key component in completion of the synthesis.

The aldehyde 14 was also derived from D-glucose through the branched alcohol. Aldol condensation of 13 with 14 gave the unsaturated keto-ester 15, which was transformed to the seco-acid, followed by lactonization according to Corey's procedure ${ }^{12}$ to give a tylonolide derivative 16, following formation of the acetal of the aldehyde group. The ethylene acetal $\mathbf{1 6}$ was submitted to initial glycosylation with D-mycaminosyl bromide 17, yielding the $\beta$-glycoside 18 after methanolysis. The second glycosylation, accomplished by our particular method, ${ }^{8,13}$ using the glycal of mycarose 19 and 1,3-dibromo-5,5-dimethylhydantoin, to give the 2-bromo-2-deoxy- $\alpha$-glycoside $\mathbf{2 0}$ followed by deprotection and debromination to afford de-mycinosyl tylosin (21). This product was also isolated from the natural sources. ${ }^{14}$ The third glycosylation, using the mycinosyl bromide 22 under Koenigs - Knorr conditions, followed by deprotection, completed the total synthesis of tylosin (4). 
The first total synthesis of 14-membered macrolide antibiotics The author's group accomplished the first total synthesis of a 14-membered macrolide antibiotic, oleandomycin (1) (Figure 4). ${ }^{15,16}$ As mentioned above, this is also based on the construction of the skeleton from carbohydrates, L- and D-rhamnosides, (23) and (24), and then cyclization by intramolecular Horner-Emmons reaction after esterification of the C1-C7 and C8-C14 segments, 27 and 28, which were derived from the enantiomeric intermediates 25 and 26. The sugar moieties $\mathbf{3 0}$ and $\mathbf{3 1}$ were regio- and stereoselectively introduced on the aglycone, oleandolide (29), to give oleandomycin (1).

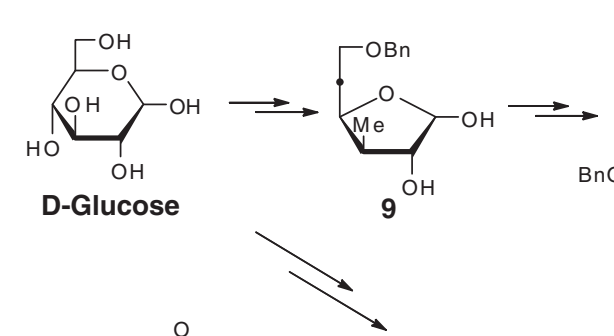<smiles>CC(=O)/C=C/C1OC(C)(C)OC(CC(O)O)C1C</smiles>

10

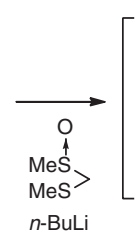

$n$-BuLi

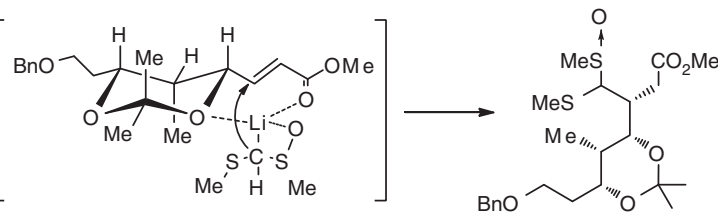

12

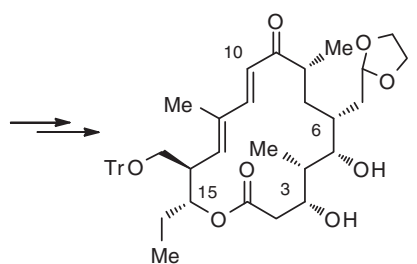

16

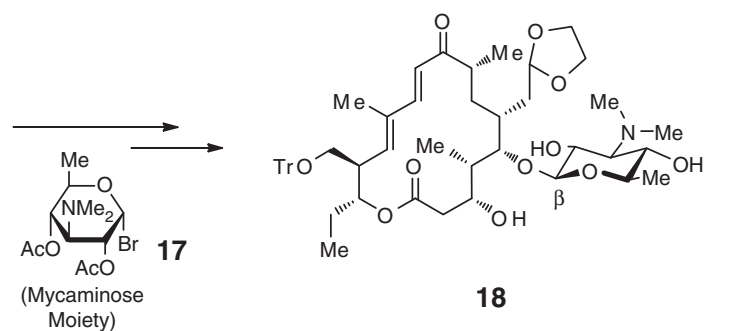

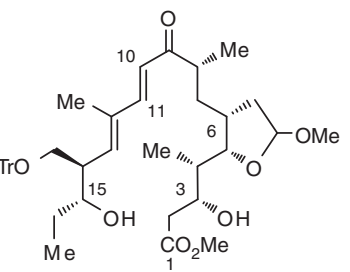

15

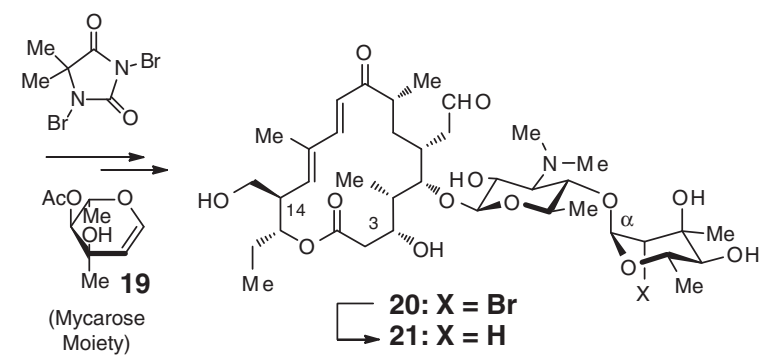

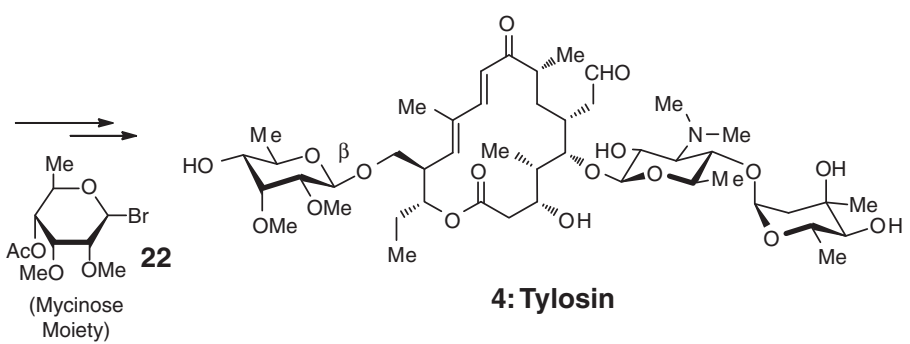

Figure 3 Total synthesis of tylosin.

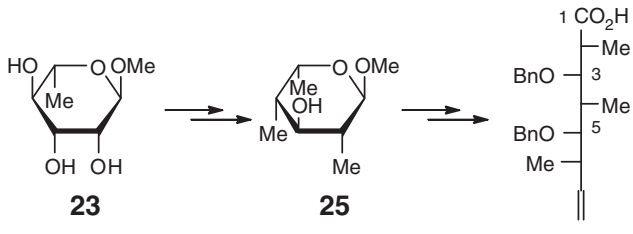

23

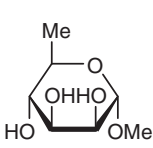

24

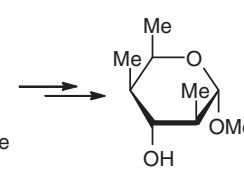

26

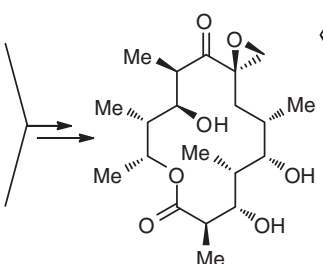

29

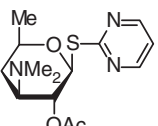

30
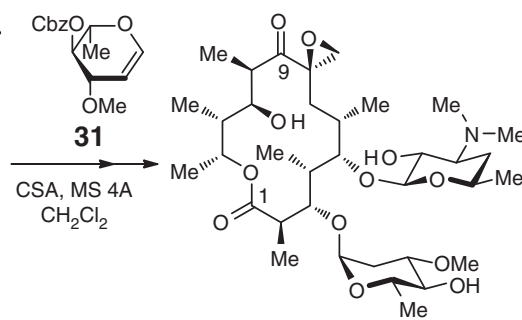

1: Oleandomycin

Figure 4 Total synthesis of oleandomycin. 
The total synthesis of erythromycin A (2) was also accomplished in our laboratories via an original stereo- and regioselective introduction of sugar moieties to the aglycone 32 (Figure 5). ${ }^{17}$ The glycosylation to the C3 hydroxyl group of 29 and erythronolide derivative 33 predictively posed an extremely difficult problem, due to the low reactivity connected with the sterically crowded nature of the $\mathrm{C} 3$ hydroxyl group and the formation of a hydrogen bond between its hydroxyl group and C1 carbonyl group. However, our glycosylation, using the 2,6-anhydro-2-thio sugar 34 worked very efficiently to give the desired $\alpha$-glycoside 35 in $92 \%$ yield. This was converted to erythromycin A (2) through desulfurization to give the 2,6dideoxyglycoside.

We also developed several other glycosylation methods to synthesize many natural products. ${ }^{18,19}$

Total synthesis of the macrolactone antibiotic, tubelactomicin A Tubelactomicin A (46) was isolated from the culture broth of Nocardia sp. MK703-102F1 and showed strong and specific antimicrobial activities against drug-resistant Mycobacterium sp. ${ }^{20}$ Its structure was determined by X-ray crystallographic analysis to be the 16-membered lactone fused with a trans-decalin skeleton. Our total synthesis was completed from L-arabinose, ${ }^{21}$ although, independently, another successful synthesis was reported. ${ }^{22}$

The stereochemical array of the northern part of the compound was derived from L-arabinose (36) (Figure 6). After stereoselective introduction of C-methyl group, the lactone $\mathbf{3 7}$ was submitted to reductive ring-opening to give the diol $\mathbf{3 8}$, possessing functionality to be the northern part 39 . The decalin moiety 43 , the southern part of tubelactomicin A, was constructed by intramolecular Diels - Alder reaction. Citronerol (40) was converted to the triene 41. The stereoselective Diels - Alder reaction to construct the additional four chiral centers was realized by heating $\mathbf{4 1}$ in xylene, which gave the adduct 42 as a single product. This was converted to 43 to couple with the northern part 39 .

Treatment of the mixture of $\mathbf{3 9}$ and $\mathbf{4 3}$ under the conditions of Suzuki coupling gave the tetraene seco-acid $\mathbf{4 4}$ after desilylation. ${ }^{23}$ The seco-acid $\mathbf{4 4}$ was submitted to the macrolactonization by the Shiina method ${ }^{24}$ to construct the lactone 45. Deprotection and selective oxidation afforded ( + )-tubelactomicin A (46).

The first total synthesis and determination of the absolute structure of $(+)$-cochleamycin A, which exhibits a unique 10-membered lactone

(+)-Cochleamycin A (58) was isolated by the Kirin Brewery group from a cultured broth of Streptomyces sp. and showed cytotoxicity against P388 leukemia cells and antimicrobial activities. ${ }^{25}$
The relative stereochemistry was elucidated and detected a 5-6-10-6-membered tetracyclic core (Figure 7). We accomplished the first total synthesis of cochleamycin A, which facilitated determination of the absolute structure, by using intramolecular Diels-Alder reaction followed by direct construction of the 10 -membered rings, ${ }^{26}$ which was well-known to be difficult. After our first total synthesis, Roush's group reported another synthesis route. $^{27}$

For maximum convergency, the acyclic precursor $\mathbf{5 2}$ of the Diels - Alder reaction was constructed by connection of two chiral segments, 48 and 50, which were prepared from a small carbohydrate 47 and (S)-1,2,4-trihydroxybutane (49), respectively, by our previously developed methodologies. ${ }^{28}$ Coupling of 48 and 50 proceeded smoothly to give the alcohol 51 in quantitative yield. This was selectively reduced to the cis, trans-diene structure, which was crucial to the construction of the desired 5-6-membered ring by intramolecular Diels - Alder reaction. Oxidation of the allylic alcohol gave the $\alpha, \beta$-unsaturated aldehyde 52, which was submitted to intramolecular Diels - Alder reaction in the presence of $\mathrm{Yb}$ (fod $)_{3}$ at $140{ }^{\circ} \mathrm{C}$. The desired adduct $\mathbf{5 3}$ was obtained as a single product in good yield. This intramolecular Diels - Alder reaction produced four critical stereocenters, as expected. The desired cyclization of the bromo-aldehyde $\mathbf{5 4}$ was accomplished with $\mathrm{SmI}_{2}$ to give the 10-6-5-membered tricyclic product 55 as a single product, comprising the fully elaborated structure ready for conversion to the cochleamycin (58). Lactonization of the seco-acid $\mathbf{5 6}$ was realized under Kita's conditions ${ }^{29}$ to afford the 10-membered lactone concomitant with the formation of the $\delta$-lactone ring. The allylic alcohol of the lactone 57 was oxidized to $\alpha, \beta$-unsaturated ketone by exposure to $\mathrm{MnO}_{2}$, followed by selective acetylation with $\mathrm{AcONa}$ and $\mathrm{Ac}_{2} \mathrm{O}$ at $60^{\circ} \mathrm{C}$ to afford $(+)$-cochleamycin $\mathrm{A}(\mathbf{5 8})$. The synthetic 58 was identical in all respects, including the optical rotation, with natural cochleamycin $\mathrm{A}$, completing the first total synthesis to establish the absolute structure.

Thus, the simplest carbohydrate $\mathbf{4 7}$ was efficiently used for the total synthesis. In addition, the first total synthesis of another tetracyclic antibiotic having a unique $\gamma$-lactone, tetrodecamycin (59), was also accomplished by using $\mathbf{4 7}$ in our laboratories. ${ }^{30}$

\section{TOTAL SYNTHESIS OF AMINOGLYCOSIDE ANTIBIOTICS}

The author's synthetic studies on antibiotics began with the determination of the absolute structure and the total synthesis of kanamycins A (5), B and C (Figure 1). ${ }^{31,32}$ Subsequently, in 1982, the author had another chance to undertake work on the total synthesis of aminoglycoside antibiotics, namely, apramycin (6) and saccharocin (69) (Figure 8).

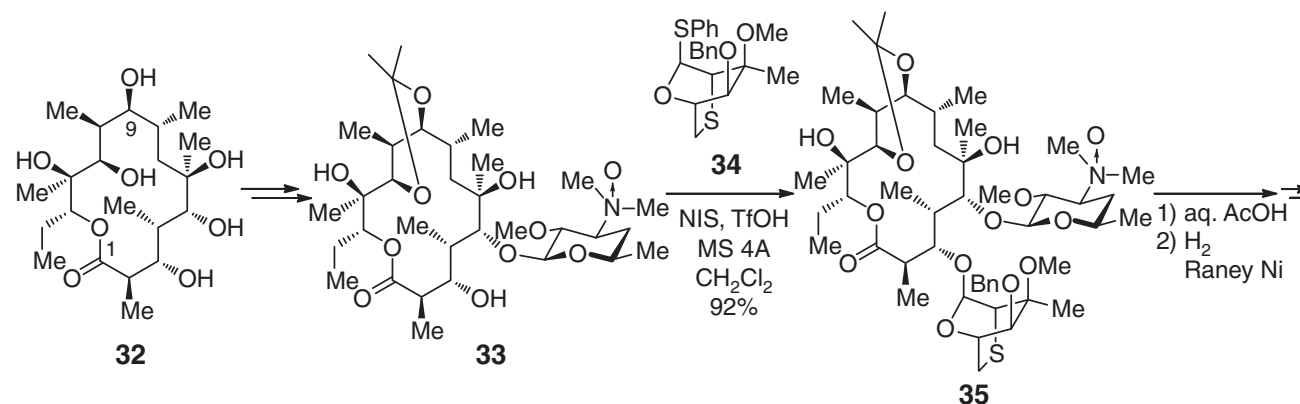

35

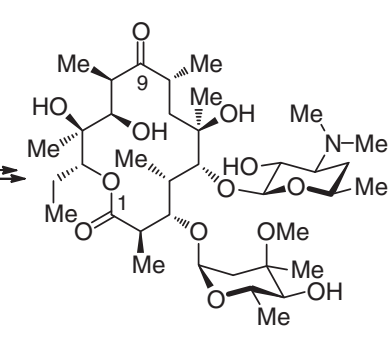

2: Erythromycin A

Figure 5 Total synthesis of erythromycin A. 


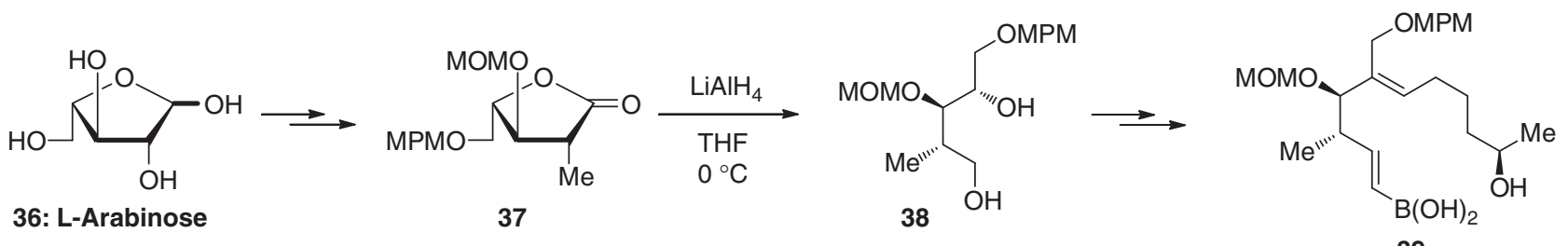

36: L-Arabinose

37

$38 \mathrm{OH}$

39

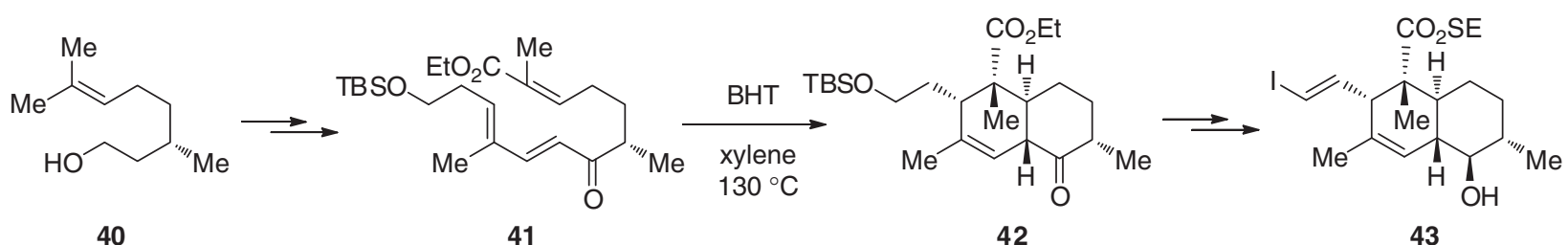

40<smiles>COCC(=CCCCC(C)O)C(OC)[C@@H](C)C=CBr</smiles>

39

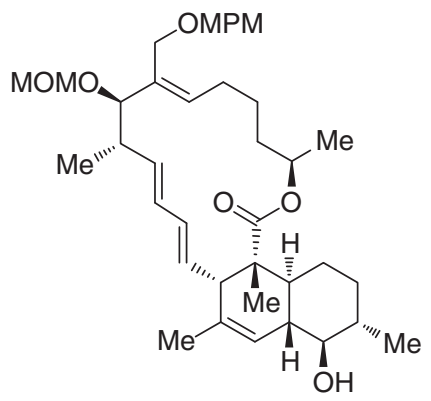

45

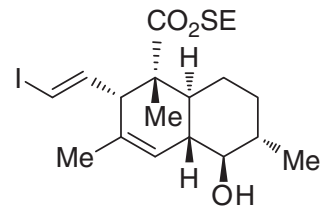

43

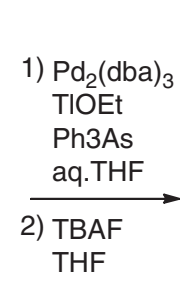

42

43<smiles>COC(=O)c1c(C)cccc1[N+](=O)[O-]</smiles>

Figure 6 Total synthesis of (+)-tubelactomicin A.

The first total synthesis of apramycin and saccharocin

Apramycin (6) and saccharocin (69) are antibiotics active against gram-positive and gram-negative bacteria, including strains resistant to other aminoglycoside antibiotics. Structurally, 6 and 69 contain the unusual bicyclic amino-octodialdose and, in addition, 4-amino-4deoxy-D-glucose and D-glucose units, respectively. ${ }^{33,34}$ The first total synthesis of apramycin and saccharocin was accomplished in our laboratories in $1983 .{ }^{35}$ Our starting point was the known aminoglycoside antibiotic, neamine $(\mathbf{6 0})$, which had already been synthesized by us. Neamine was converted into the aldehyde 61 by effective oxidation of the primary amino group (Figure 8). The aldehyde $\mathbf{6 1}$ was converted by our carbon-elongation method to the acetyl glycal 62. This was submitted to azidonitration using sodium azide and ammonium ceric nitrate to give azidoglycosyl nitrate $\mathbf{6 3}$. The C3 position of the dimesylate $\mathbf{6 4}$ was selectively chlorinated to form the $3^{\prime}$-chloro compound, which was dechlorinated with tributylstannane to give the $3^{\prime}$-deoxy compound 65. Epimerization of the $6^{\prime}$-hydroxy group, by heating $\mathbf{6 5}$ with sodium acetate trihydrate, yielded the cis cyclic carbamate $\mathbf{6 6}$ needed for the apramycin skeleton. Removal of all protecting groups gave aprosamine $(67: \mathrm{Z}=\mathrm{H})$, which was $N$-benzyloxy-carbonylated to 67 . In the glycosylation studies on 67, the best result was realized under modified Mukaiyama conditions $^{36}$ using 4 -azido-2,3,6-tri-O-benzyl-4-deoxy- $\beta$-D-glucopyranosyl fluoride (68) to give the glycoside, subsequently deprotected by hydrogenolysis to furnish apramycin.

Similarly, saccharocin was synthesized by glycosylation of $\mathbf{6 7}$ with 2,3,4,6-tetra-O-benzyl- $\beta$-D-glucopyranosyl fluoride.

\section{TOTAL SYNTHESIS AND DEVELOPMENTS OF $\beta$-LACTAM ANTIBIOTICS}

The molecular architecture associated with the $\beta$-lactam antibiotics has posed some of the greatest challenges in synthetic chemistry, and this family has provided the stimulus for development of novel methodologies for construction of their skeletons and side chains (Figure 9). Among the cephem antibiotics, the fourth generation has been especially noteworthy (Figure 10).

Total synthesis of the $\beta$-lactam antibiotic, $(+)$-thienamycin Thienamycin (7) was discovered in fermentation broths of Streptomyces cattleya and showed exceptional antibacterial potency 
<smiles>C#CC(OC)C(C)C/C=C/CO</smiles>

47<smiles>C#CC(OC)C(C)C/C=C/CO</smiles>

50

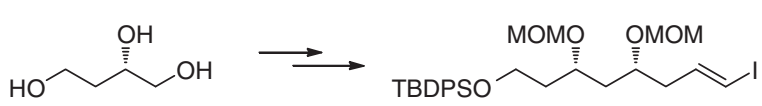

49 50
1) $\mathrm{Zn}, \mathrm{BrCH}_{2} \mathrm{CH}_{2} \mathrm{Br}$ $\mathrm{LiCuBr}_{2}$ EtOH-THF

2) IBX PhMe-DMSO

51

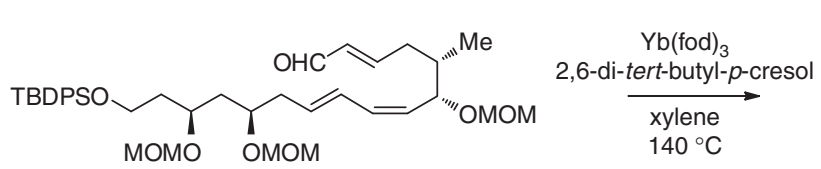

52

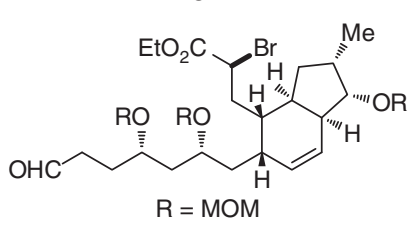

54

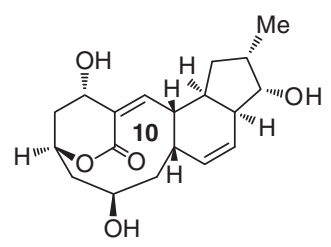

57

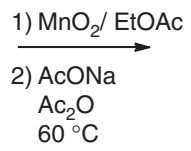
$\mathrm{Ac}_{2} \mathrm{O}$
$60^{\circ} \mathrm{C}$

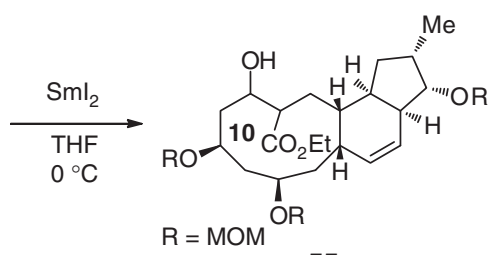

55

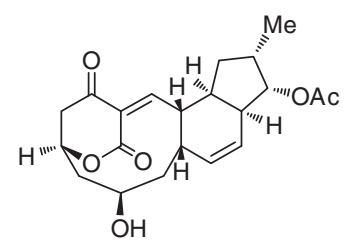

58: Cochleamycin A

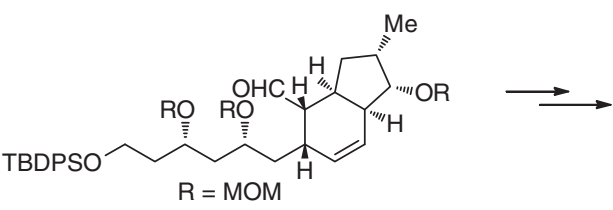

53

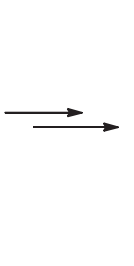

2)

59: Tetrodecamycin

Figure 7 Total synthesis of cochleamycin A and tetrodecamycin.

and spectrum. ${ }^{37}(+)$-4-Acetoxy-3-hydroxyethyl-2-azetidinone $(\mathbf{8 0})$ has been well-known as a highly versatile intermediate for the synthesis of carbapenem antibiotics, such as thienamycin (Figure 9). ${ }^{38}$ The synthesis of $\mathbf{8 0}$ was initiated by the Sankyo group, followed by the Merck group, and culminated in the practical preparation by two Japanese companies, using Noyori-Murahashi's asymmetric procedures and chem-enzymatic procedures, respectively. ${ }^{38}$ The first stereocontrolled synthesis of $(+)$-thienamycin (7) was reported by the Merck group, and the transformation of $\mathbf{8 0}$ to $\mathbf{7}$ was also made more attractive by a second Merck group. Consequently, the synthesis of the azetidinone $\mathbf{8 0}$ constitutes a formal total synthesis of $(+)$-thienamycin $(7) .{ }^{39,40}$

We reported a novel enantiospecific synthesis of $\mathbf{8 0}$ from a carbohydrate through our developed skeletal rearrangement and stereoselective epimerization (Figure 9). ${ }^{41}$ Our starting material was the commercially-available methyl 2-amino-2,6-dideoxy- $\alpha$-D- glucopyranoside (70), which has also been isolated from natural sources. ${ }^{41}$ Reaction of $\mathbf{7 0}$ with $\boldsymbol{o}$-benzenedisulfonyl dichloride gave the cyclic sulfonate 71 , which was submitted to our skeletal rearrangement, including ring-contraction with potassium tert-butoxide. The resulting 3-formyl-furanoside $\mathbf{7 2}$ was oxidized to the carboxylic acid 73 in $91 \%$ yield. Removal of the $N$-sulfonyl group of 73 by Birch reduction produced the corresponding amino acid 74 . This was hydrolyzed and then esterified to give the furanose 75 . Oxidation of
75 to the lactone 76 was the key step of our strategy, although the lactone could not be obtained under usual oxidation conditions. We finally discovered that, on exposure to $\mathrm{Ag}_{2} \mathrm{CO}_{3} /$ Celite in benzene, 75 was smoothly oxidized to the $\gamma$-lactone $\mathbf{7 6}$ despite the presence of the amino group.

The next important operation in the synthesis was to epimerize stereoselectively and simultaneously the configurations at the $\mathrm{C} 2$ and C3 positions of 76 . The best result was realized by using DBU in $\mathrm{MeOH}$ to afford predominantly the desired amino ester 77 . This result indicated that the $\mathrm{C} 4$ configuration of 76 controlled the stereoselective construction of the $\mathrm{C} 2$ and $\mathrm{C} 3$ configurations of 77. Hydrolysis with $2 \mathrm{~m} \mathrm{NaOH}$ led to the hydroxy acid 78, which was in turn submitted to the $\beta$-lactam formation. For our purpose, a Grignard-mediated cyclization of the silylated derivative seemed most promising. Thus, $\mathbf{7 8}$ was silylated with trimethylsilyl chloride and hexamethyldisilazane, followed by treatment with tert-butylmagnesium chloride to give the bis-silylated $\beta$-lactam 79. Oxidative decarboxylation by $\mathrm{Pb}(\mathrm{OAc})_{4}$ gave exclusively the desired $(+)-4$ acetoxy-3-hydroxyethyl-2-azetidinone (80), with removal of silyl groups. This was identical in all respects to the authentic sample. Overall, the yield was $\sim 35 \%$ in 11 steps from 70 . Key steps include our original skeletal rearrangement with ring-contraction, oxidation of the 2-aminofuranose, and stereoselective epimerization to the desired configurations. 


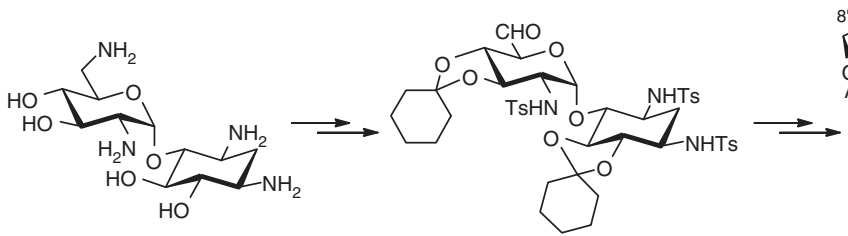

60: Neamine

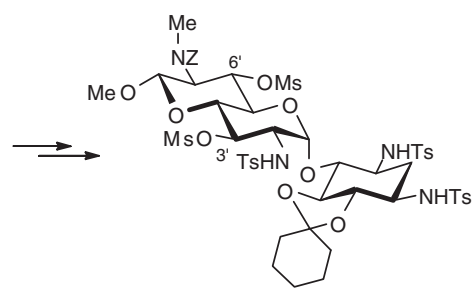

64
61

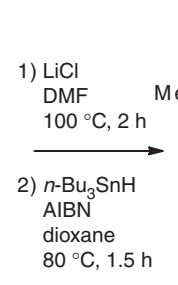

dioxane $80^{\circ} \mathrm{C}, 1.5$

$\mathrm{OBn}$
65

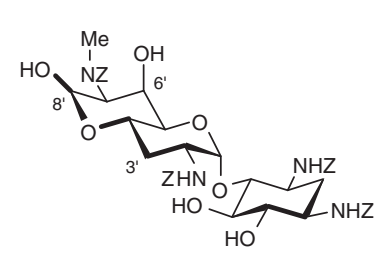

67 (Aprosamine: $Z=H$ )

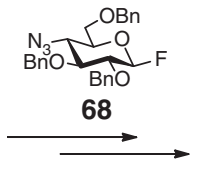

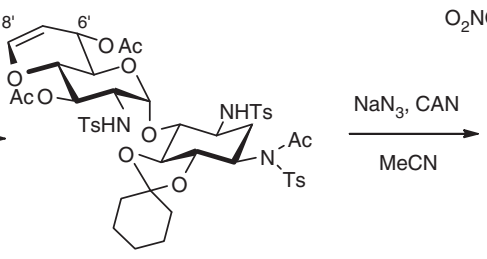

62
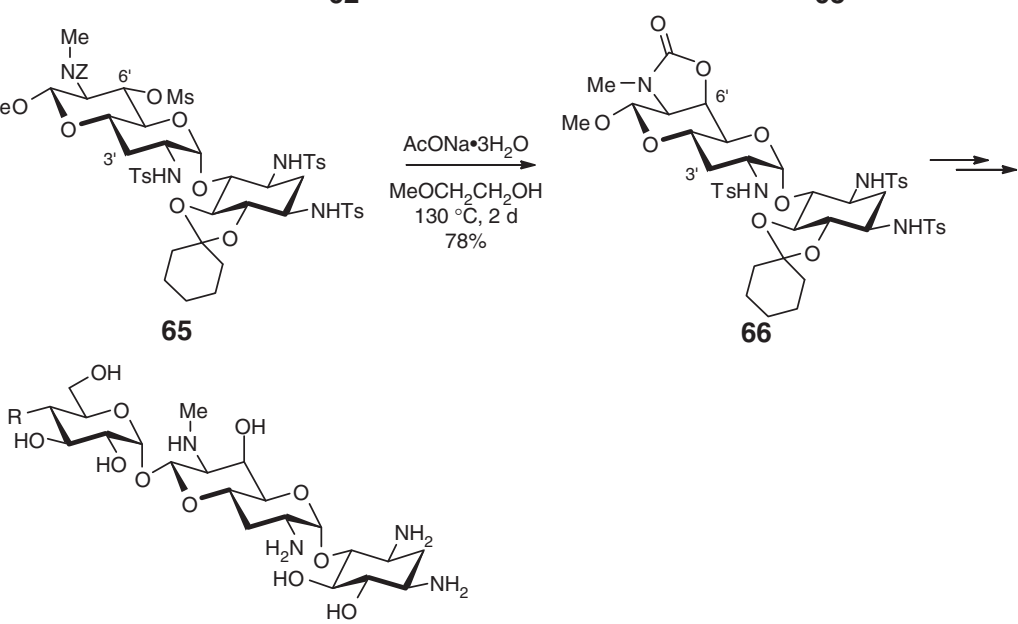

6: Apramycin : $\mathrm{R}=\mathrm{NH}_{2}$

69: Saccharocin : $\mathrm{R}=\mathrm{OH}$

Figure 8 Total synthesis of apramycin and saccharocin.
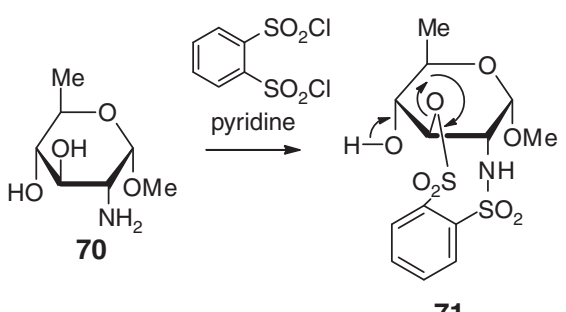

71
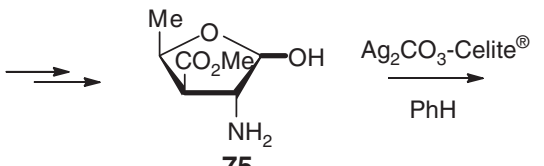

75
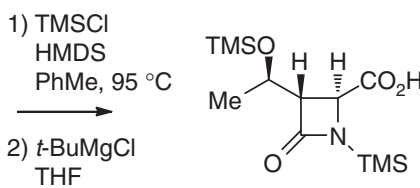

79
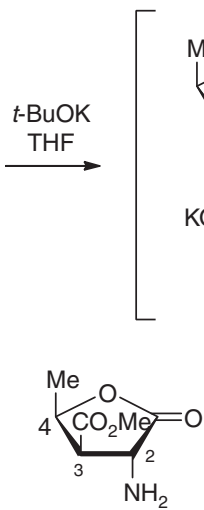

76

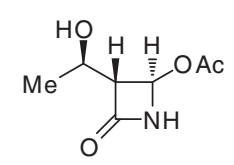

80

72
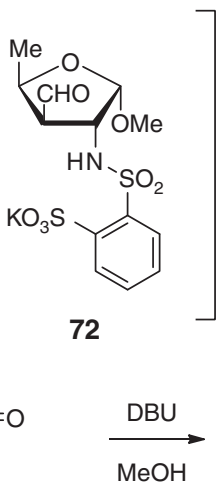

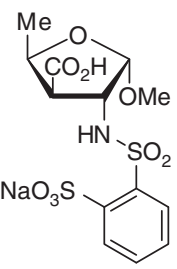
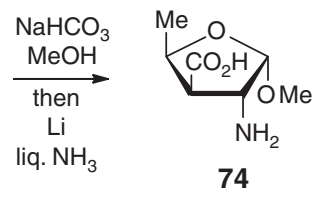

73

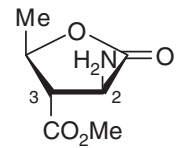

77

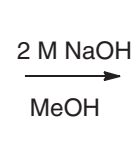<smiles>CC(O)[C@H]1C(=O)N2C(C(=O)O)=C(SCCN)C[C@H]12</smiles>

7: Thienamycin

Figure 9 Total synthesis of thienamycin.

Practical preparation of (Z)-2-(5-amino-1,2,4-thiadiazol-3-yl)-2methoxy- iminoacetic acid, a side-chain of the fourth generation of cephem antibiotics

Recently, (Z)-7 $\beta$-(2-(5-amino-1,2,4-thiadiazol-3-yl)-2-(alkoxyimino)acetamido)-cephalosporins, such as cefozopran (89), have been reported as clinically useful antibiotics having excellent antimicrobial activities. $^{42}$ Their common acyl moiety at the C7 position corresponds to the Z-isomer (for example, 88) of 2-(5-amino-1,2,4- thiadiazol-3-yl)-2-(alkoxyimino)acetic acid (Figure 10). The E-isomer is known to be of little value for $\beta$-lactam antibiotic use. Consequently, it was our intention to successfully develop a novel general method of entry into the Z-isomer, even though several methods have already been reported for the production of $\mathbf{8 8}$.

We devised a novel and concise preparation directed toward the mass production of the (Z)-methoxyimino compound: (Z)-2-(5amino-1,2,4-thiadiazol-3-yl)-2-(methoxyimino)acetic acid (88) based 


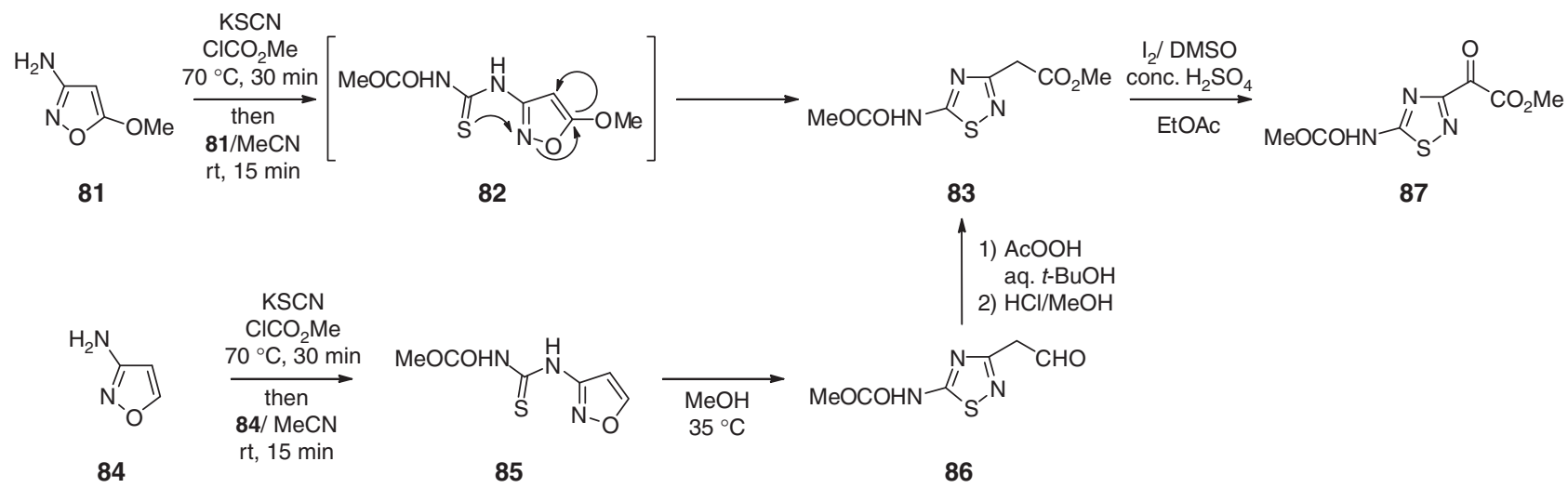<smiles>CC(=O)ONc1nc(C(=O)OC(C)=O)ns1</smiles>

87

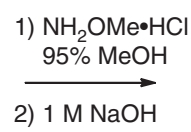

2) $1 \mathrm{M} \mathrm{NaOH}$<smiles>CO/N=C(\C(=O)O)c1nsc(N)n1</smiles>

88

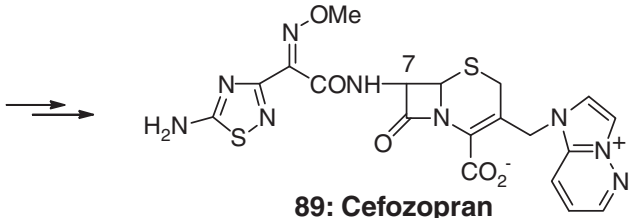

89: Cefozopran

Figure 10 Practical preparation of a side-chain of the fourth generation of cephem antibiotics.

on the skeletal rearrangement of the aminoisoxazoles 81 or 84 , and stereoselective formation of $\mathbf{8 8}$ (Figure 10). ${ }^{43,44}$ 3-Amino-5methoxyisoxazole (81) was subjected to the skeletal rearrangement in question. A suspension of methyl chloroformate and potassium thiocyanate in acetonitrile was stirred at $70^{\circ} \mathrm{C}$ for $30 \mathrm{~min}$ to give methoxycarbonyl isothiocyanate in situ, which in turn reacted with 81 to afford methyl 2-(5-methoxycarbonylamino-1,2,4-thiadiazol3 -yl)acetate (83) in $86 \%$ yield, through skeletal rearrangement of the intermediary thiourea derivative $\mathbf{8 2}$. This reaction mechanism was reasonably supported by the isolation of the similar intermediate $\mathbf{8 5}$ from 3-aminoisoxazole (84). The compound 85 was also converted to $\mathbf{8 3}$ through 86. Oxidation of $\mathbf{8 3}$ gave the 2-oxoacetate $\mathbf{8 7}$ (with DMSO and $\mathrm{I}_{2}$ in the presence of catalytic amounts of $\mathrm{H}_{2} \mathrm{SO}_{4}$ ) in $83 \%$ yield. The moderate yield was ascribed to purification difficulties due to their polar nature. Without isolation of the keto-ester 87, the methyl ester 83 was quantitatively converted into the desired $Z$-isomer of 2-(methoxyimino)acetate. Saponification provided the target product $\mathbf{8 8}$ in quantitative yield. This was derived to cefozopran (89), which was marketed in $1995 .{ }^{45}$

\section{CHALLENGE TO THE TOTAL SYNTHESIS OF TETRACYCLINE ANTIBIOTICS AND RELATED ANTIBIOTICS}

For almost half a century, tetracycline (8) has been widely recognized as a major antibiotic, due to both its unique structural features as well as antibacterial activities. ${ }^{46}$ The total synthesis of tetracycline families was initiated by Woodward's 6-demethyl-6-deoxytetracycline synthesis in 1962, followed by Muxfeldt's terramycin synthesis in 1968, culminating Stork's 12a-deoxytetracycline synthesis in 1996. ${ }^{1,47}$ However, all these syntheses have been accomplished only in racemic forms. The total synthesis of natural ( -$)$-tetracycline $(\mathbf{8})$ remained an unanswered challenge, despite the remarkable achievements as described above. In 2000, the first total synthesis of (-)-tetracycline (8) was completed in our laboratories using D-glucosamine as a chiral starting material, which allows stereospecific construction of the densely and sensitively functionalized A ring (Figure 18). ${ }^{48}$ In 2005, Myers' group presented the second synthesis of $(-)$-tetracycline. ${ }^{49}$
Before and during the challenge to the total synthesis of tetracycline, we have been synthesizing naphthoquinone antibiotics to develop our own methodologies for the construction of the skeleton. Namely, pyranonaphthoquinone antibiotics (90-95) were synthesized by unique strategies including Michael - Dieckmann cyclization. After the tetracycline synthesis, the author completed the first total synthesis of a furanonaphthoquinone antibiotic, lactonamycin (120), and a pseudo-dimer of tetracycline, hibarimicinone (150), which represented the culmination of synthetic strategies and methodologies on antibiotics by the author.

\section{Total synthesis of naphthoquinone-related antibiotics using} carbohydrates and novel strategies

Pyranonaphthoquinone antibiotics (90-95) have been shown to possess significant antimicrobial, antifungal and antitumor activities (Figure 11). Structurally, the stereo-alignment of nanaomycin D (91) is included in nanaomycin A (90) and BE-54238B (95), while that of kalafungin (92) is in medermycin (93) and BE-52440A (94). The representative antibiotics are nanaomycin A (90) and D (91), which were isolated and developed by Ōmura's group. ${ }^{50,51}$ Moreover, a furanonaphthoquinone antibiotic, lactonamycin (120), was found to have the hexacyclic system and the glycosidic bond at the tertiary alcohol. These unique structures have drawn attention both for their synthesis using new methodologies and for the creation of novel biologically active compounds. The author's group accomplished the first total syntheses of these antibiotics, and developed a synthetic strategy for the stereoselective construction of densely-functionalized naphthoquinones using carbohydrates. ${ }^{2-6}$

The first total synthesis of nanaomycin $D$ and its enantiomer, kalafungin-the 'enantiodivergent' total synthesis. Carbohydrates have been used widely as chiral sources in stereospecific syntheses of natural products, as mentioned above. ${ }^{1-6}$ Although various carbohydrates are available, in most of them one enantiomer is abundant while another isomer is difficult to get in much quantity. Thus, it is hoped that both enantiomeric chiral synthons in the total synthesis are derived from only one abundant enantiomer of a 
<smiles>CC1OC(CC(=O)O)CC2=C1C(=O)c1c(O)cccc1C2=O</smiles>

90: Nanaomycin A<smiles>[M]C1O[C@@H]2CC(=O)O[C@H]2C2=C1C(=O)c1ccc(C3C[C@H](N(C)C)[C@H](O)C([Y16])O3)c(O)c1C2=O</smiles>

93: Medermycin<smiles>C[C@H]1O[C@@H]2CC(=O)O[C@@H]2C2=C1C(=O)c1cccc(O)c1C2=O</smiles>

91: Nanaomycin D

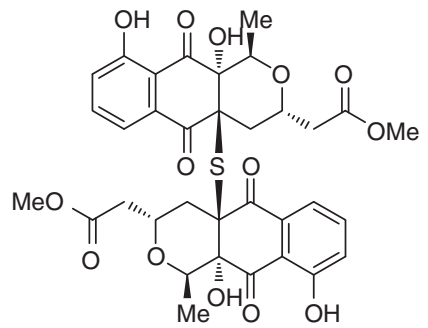

94: BE-52440 A<smiles>[Y4]C1O[C@@H]2CC(=O)O[C@H]2C2=C1C(=O)c1cccc(O)c1C2=O</smiles>

92: Kalafungin

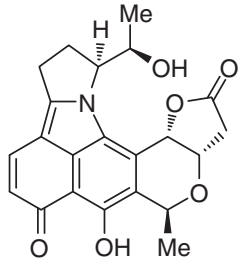

95: BE-54238B

Figure 11 Representative pyranonaphthoquinone antibiotics.

carbohydrate. During synthetic studies on nanaomycin D (91) and its enantiomer, kalafungin (113), in our laboratories, a new methodology was developed to enable synthesis of both enantiomers from a single enantiomeric carbohydrate, creating 'enantiodivergent synthesis. ${ }^{52-54}$ The critical point of the methodology was catalytic isomerization of stereocenters (Figure 12). On the protected hydroquinone 96, the isomerization at the $\mathrm{C} 3$ position was carried out to obtain the lactone 97 by elimination-recyclization equilibrium under basic conditions. Using the quinone 98, the isomerization at $\mathrm{C} 1$ and $\mathrm{C} 4$ positions was realized to afford the lactone $\mathbf{9 9}$ by enolization - protonation equilibrium under acidic conditions. This methodology was widely applied to the construction of pyranonaphthoquinone antibiotics. The enantiodivergent synthesis of nanaomycin D (91) and kalafungin (92) based on this strategy is shown in Figure 13. ${ }^{52-54}$

Methyl L-rhamnoside (100) was converted into the 2,3-di-Ocarbonyl-4-O-tosyl derivative $\mathbf{1 0 1}$ in $80 \%$ overall yield in a one pot reaction, with trichloromethyl chloroformate and then tosyl chloride in pyridine (Figure 13). Treatment of $\mathbf{1 0 1}$ with zinc powder and sodium iodide in reflux aqueous acetonitrile gave the unsaturated alcohol 102. This olefin formation was also developed in our laboratories. Oxidation of $\mathbf{1 0 2}$ with pyridinium chlorochromate afforded the stable $\alpha, \beta$-unsaturated ketone 103. Michael-Dieckmann condensation of 103 with 4-methoxy-3-(phenylsulfonyl)-1(3H)-isobenzofuranone prepared by Hauser's procedures gave naphthopyranone 104, which was transformed to the lactol 105 in three steps. The lactol 105 was submitted to Wittig reaction, which afforded the cis-lactone 106 and the trans-hydroxyl ester 107. The lactone 106 was oxidized to the quinone 108, which was subsequently de-O-methylated to give nanaomycin D (91). The hydroxyl ester 107 was converted to the quinone 109 , which was subjected to the abovementioned acidic isomerization to produce kalafungin (92), the enantiomer of nanaomycin D (91).

The first total synthesis of BE-52440A and nanaomycin E. (+)-BE$52440 \mathrm{~A}$ (94) was reported as an antitumor agent, produced by a Streptomyces strain, by the Banyu group in $2000 .{ }^{55}$ The structure was identified as a dimer of nanaomycin derivatives bridged with sulfur (Figure 14), although the relative configuration remained unknown. The first total synthesis of $\mathbf{9 4}$ was accomplished by us to help determine the absolute structure. ${ }^{56}$ We assumed that 94 would be biogenetically synthesized by epoxy-opening dimerization of OM-173 $\alpha \mathrm{E}$ (111), which was isolated by the Ōmura group. ${ }^{57}$ It was possible to obtain the antibiotic $\mathbf{1 1 1}$ by stereospecific epoxydation of pyranonaphthoquinone 110, which could be derived from the lactone 106 and $\gamma$-hydroxyester 107 by our enantiodivergent strategy, as mentioned above. ${ }^{52-54}$ The key reaction sequence is a regioselective epoxy-opening dimerization of the tetra-substituted 111 with $\mathrm{Na}_{2} \mathrm{~S}$ by $\mathrm{S}_{\mathrm{N}} 2$ reaction of the intermediary tert-thiolate.

Firstly, both enatiomeric intermediates $((-)$ - and $(+)-110)$ were selectively synthesized from the key intermediates 106 and 107. Subsequent epoxidation afforded $(+)-$ and (-)-OM-173 $\alpha \mathrm{E}$ $((+)$ - and $(-)-111)$. The one epimer, $(+)-111$, was hydrolyzed to natural $(+)$-nanaomycin $\mathrm{E}(\mathbf{1 1 2}),{ }^{58}$ which was also isolated by Ömura's group, while the other $(-)-111$, on treatment with $\mathrm{Na}_{2} \mathrm{~S}$, was converted to natural ( + )-BE-52440A (94). Thus, their absolute structures were determined.

The first total synthesis of BE-54238B - the iminoquinone isomerization. We achieved the enantioselective total synthesis of BE-54238B (95) to confirm its absolute structure (Figure 15). ${ }^{59}$ The bromo precursor 113 was prepared as mentioned above for the synthesis of nanaomycin D (91). The 113 was lithiated to couple with the L-pyroglutamic acid derivative 114 to obtain the ketone 115. After construction of the pyrrolidine 116, Wittig reaction gave the cis-lactone 117 and the trans-hydroxyl ester, in $67 \%$ and $22 \%$ yields, respectively. The lactone 117 was suitable for the synthesis of the natural product 95, while the hydroxyester could also be transformed to 117 in high yield by heating with $\mathrm{KHCO}_{3}$ and 18-crown-6 in dimethylformamide. Acidic removal of two Boc groups in $\mathbf{1 1 7}$ was followed by oxidative de-Omethylation to give the quinone 118. This was effectively cyclized to the hexacyclic product $\mathbf{1 1 9}$ through proton-tautomerization. This was de-O-methylated by $\mathrm{BCl}_{3}$ to give the retautomerized compound 95, which was identical in all respects with natural BE-54238B.

The first total synthesis of a furanonaphthoquinone antibiotic, lactonamycin. Lactonamycin (120, Figure 16) was isolated from a culture broth of Streptomyces rishiriensis MJ773-88K4 by Matsumoto et al. ${ }^{60}$ in 1996. Lactonamycin (120) showed potent antimicrobial activities against gram-positive bacteria including methicillin-resistant Staphylococcus aureus and vancomycin-resistant Enterococcus as well 

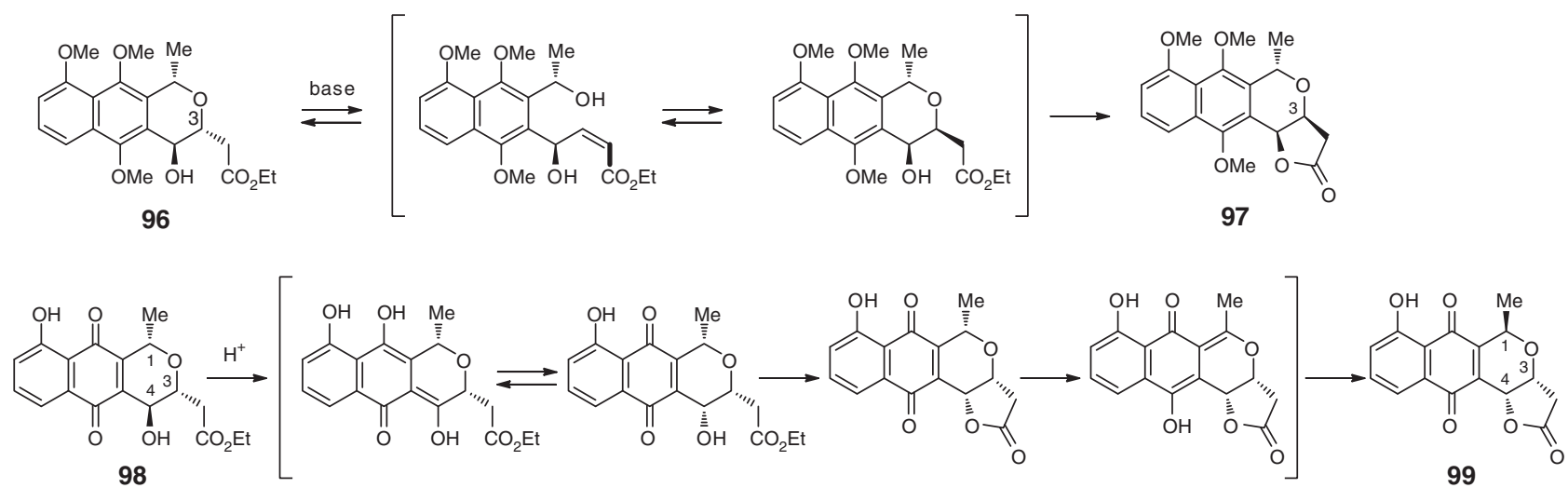

Figure 12 Enantiodivergent methodologies for synthesis of pyranonaphthoquinone skeletons.

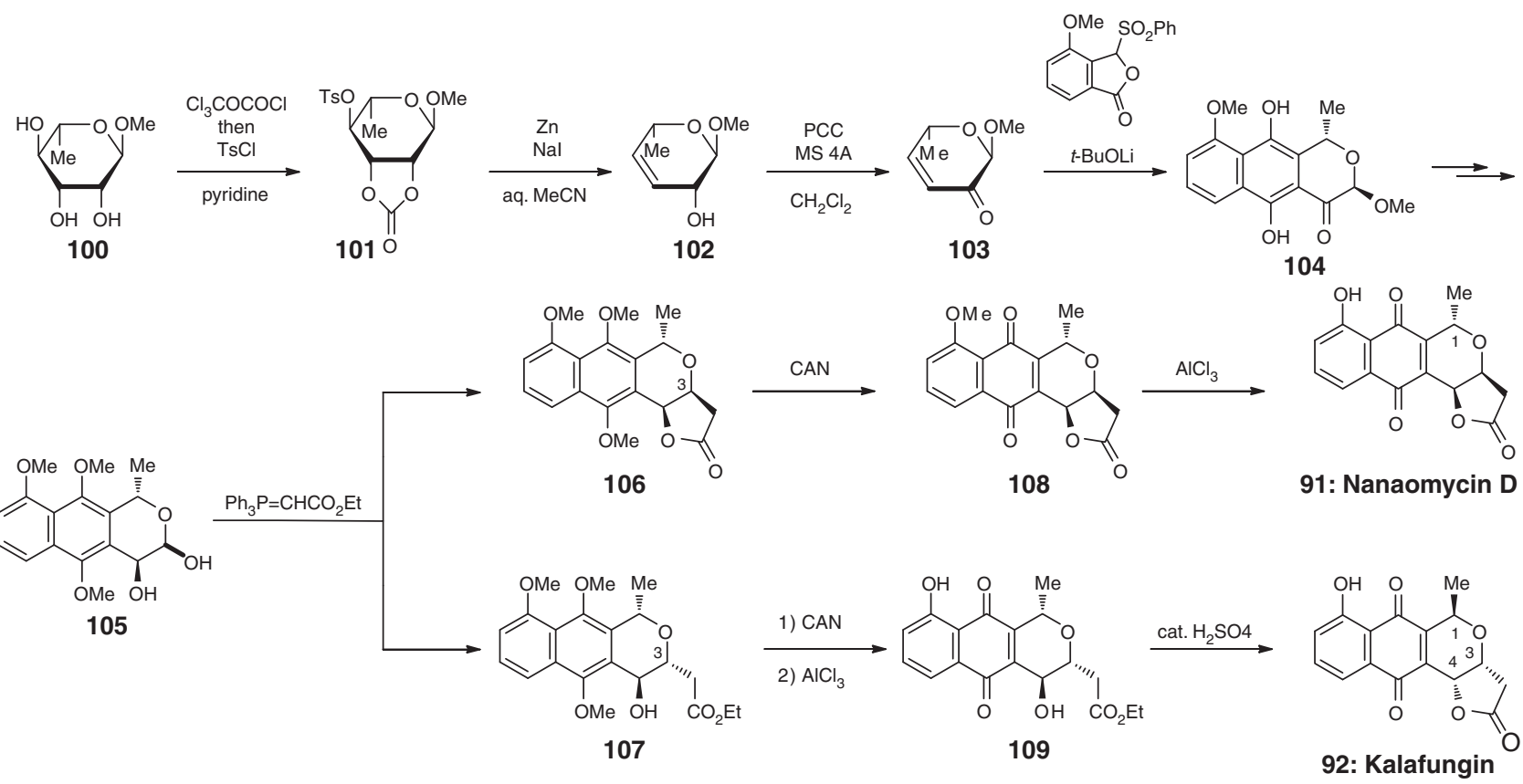

Figure 13 Enantiodivergent total synthesis of nanaomycin D and its enantiomer, kalafungin.

as antitumor activities. ${ }^{60,61}$ The unique structure of 120 was determined by X-ray crystallography and degradation studies. By the remarkable structure and activities, many groups have been attracted and challenged to synthesize this compound, ${ }^{62,63}$ nevertheless, the total synthesis has been unprecedented.

We accomplished the first total synthesis of lactonamycin (120) through Michael-Dieckmann type cyclization. ${ }^{64}$ The stereoselective glycosylation of the tertiary alcohol with the 2,3-deoxysugar is challenging, and rhodinose derivative $\mathbf{1 2 3}$ was used as a resolving agent for racemic 121 .

Thioester 122 corresponding to the DEF segment was synthesized from 4-bromo-3,5-dimethylphenol 124 (Figure 17). O-Methylation of 124 and subsequent lithiation followed by methoxycarbonylation gave the ester 125, which was taransformed to the bicyclic 126. After exchange of $\mathrm{O}-\mathrm{Me}$ to $\mathrm{O}-\mathrm{Bn}$ group, the bromide was converted into the sulfone 122 .

The synthesis of the ABC segment 121 started from mono-Omethyl-dihydroxybenzoic acid 127 (Figure 17). Reduction of methyl ester and the successive oxidation of the aromatic ring in the presence of ethylene glycol gave quinone mono-acetal 128. Dihydroxylation of the tri-substituted olefin of $\mathbf{1 2 8}$ provided the triol, which was subjected to stereoselective reduction and protection to obtain the diol 129. After oxidation of the secondary alcohol of 129 , the tertiary alcohol was protected as triethylsilyl ether to yield 130. Methyl propiolate was introduced in the stereospecific manner under the basic conditions to give the cis-tertiary diol 131. De-silylation and the conjugate addition of the resulting primary alcohol proceeded to afford 132. Treatment of the ester 132 in methanol under the acidic conditions to give the $\gamma$-lactone, followed by oxidation to the 1,4 diketone 121 .

Rhodinose thioether derivative $\mathbf{1 2 3}$ was synthesized from L-rhamnal through Ferrier reaction and inversion of the configuration of the secondary alcohol by Mitsunobu reaction.

The racemic 121 was subjected to glycosylation with 123 in the presence of silver triflate ${ }^{18}$ to give a diastereomeric mixture of only $\alpha$-glycosides under a strong anomeric effect (Figure 17). The mixture was separated by silica gel column chromatography to give the optically pure $\mathbf{1 3 3}$ in $42 \%$ (practically $84 \%$ ).

Michael-Dieckmann type condensation ${ }^{2-6}$ of the enone 133 with the thioester $\mathbf{1 2 2}$ gave the protected lactonamycin 134 . 


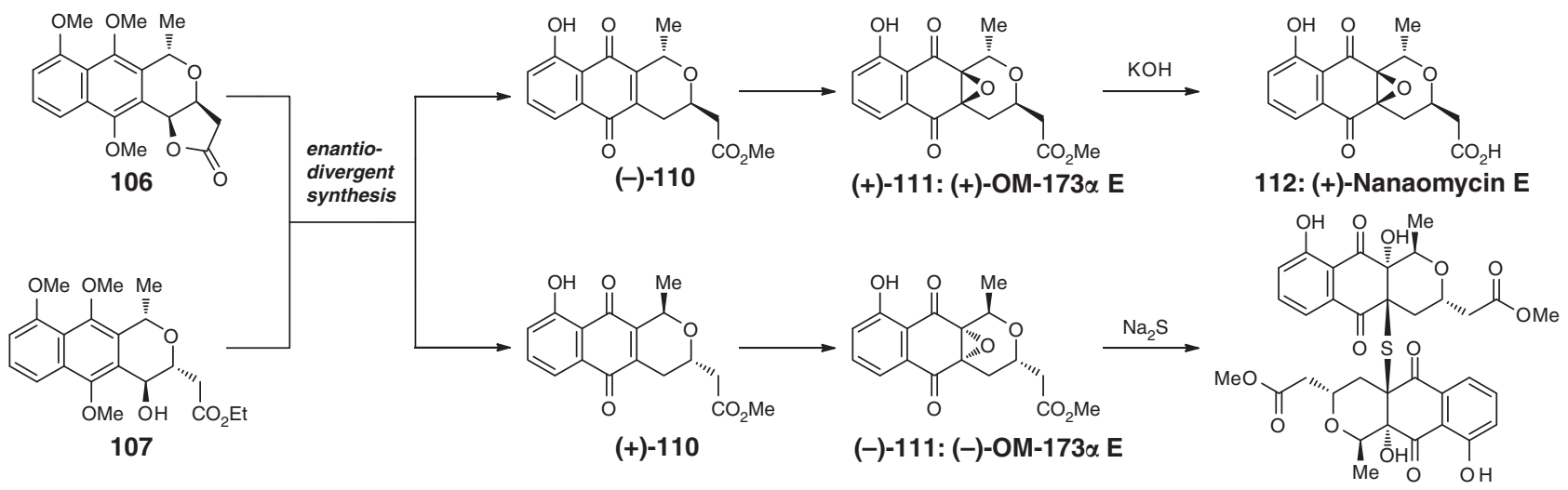

94: (+)-BE-52440A

Figure 14 Total synthesis of OM-173 E, nanaomycin E and BE-52440A.<smiles>COc1ccc(Br)c2c(OC)c3c(c(OC)c12)[C@H](O)[C@H](Cc1ccccc1)O[C@H]3Cc1ccccc1</smiles>

113

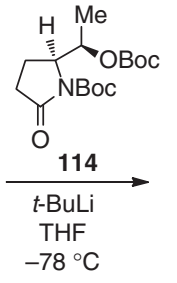

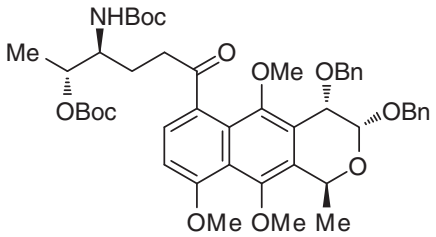

115<smiles>C=CC(C)C</smiles><smiles>COc1ccc([C@H]2CC[C@H](C(C)OC(C)=O)[C@@H]2O)c2c(OC)c3c(c(OC)c12)C(C)OC(O)[C@H]3O</smiles><smiles>CCOC(=O)c1ccccc1</smiles>

116

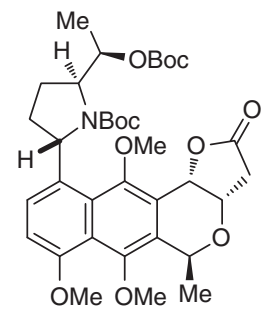

117

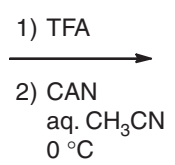

$0^{\circ} \mathrm{C}$<smiles>COc1ccc([C@H]2CC[C@H](C(C)O)[C@H]2O)c2c1C(=O)C1=C(C2=O)[C@@H]2OC(=O)C[C@H]2OC1C</smiles>

118

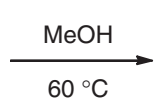

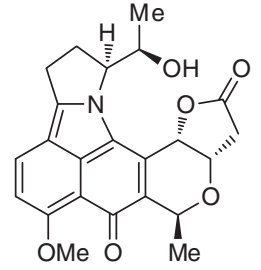

119

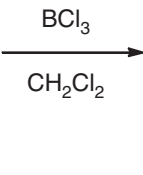

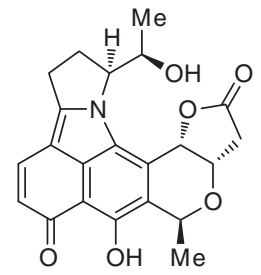

95: BE-54238B

Figure 15 Enantiodivergent total synthesis of BE-54238B.

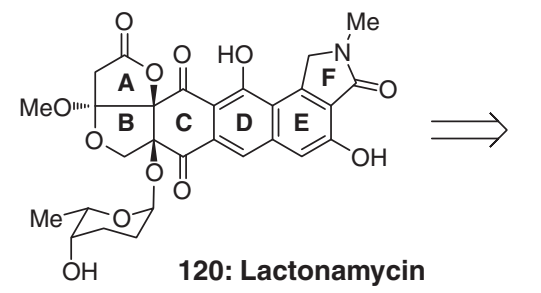

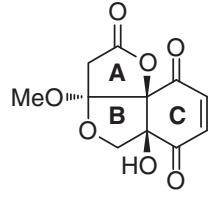

121<smiles></smiles>

122<smiles>COC(COCc1ccccc1)COCC(C)O</smiles>

123

Figure 16 Retrosynthesis of lactonamycin.

Hydrogenolysis of 134 afforded lactonamycin (120), completing the total synthesis.

The first total synthesis of natural ( -)-tetracycline Anhydrotetracycline (147) was our first target (Figure 18) ${ }^{48,65}$ as it provides a viable synthetic relay from 147 to tetracycline (8) via a two-step hydration at the $5 \mathrm{a}, 6$-position. ${ }^{47} \mathrm{~A}$ reliable $12 \mathrm{a}$ hydroxylation is required for the synthesis of 147 . The startingpoint glucosaminide 135, which was prepared from D-glucosamine, was converted into the selenide $\mathbf{1 3 6}$. Treatment of $\mathbf{1 3 6}$ with borane followed by $\mathrm{H}_{2} \mathrm{O}_{2}$ oxidation stereoselectively gave the alcohol by simultaneous formation of a new olefin group, which was benzylated to the olefin 137. This was submitted to Ferrier reaction with $\mathrm{HgCl}_{2}$ to give the cyclohexanone 138. The $[4+2]$ cycloaddition of the cyclohexenone, which was derived from 138 by dehydration, with the butadiene 140 did not proceed because of the steric repulsion. Therefore, $\mathbf{1 3 8}$ was epimerized at C2 and dehydrated to the isomer 139. The $\alpha$-hydroxymethyl group was an important factor for 


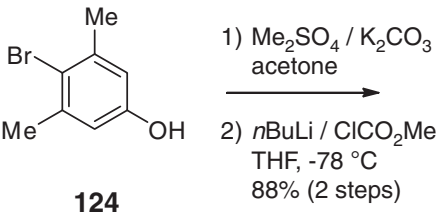

124<smiles>COC(=O)c1c(C)cc(OC)cc1C</smiles>

125<smiles>COC(=O)c1c(CBr)cc(OC)c2c1CN(C)C2=O</smiles>

126<smiles>CCCCOc1cc(CS(=O)(=O)OC)c(C(=O)CC)c2c1C(=O)N(C)C2</smiles>

122<smiles>COC(=O)c1cc(OC)ccc1O</smiles>
127<smiles>O=C1C=CC2(C=C1CO)OCCO2</smiles>

1) $\mathrm{OsO}_{4} / \mathrm{NMO} \cdot \mathrm{H}_{2} \mathrm{O}$ acetone

2) $\mathrm{NaBH}_{4} / \mathrm{MeOH}$

3) $\overleftrightarrow{\mathrm{TBSCl} / \text { imidazole }}$ DMF $50 \%$ (3 steps)

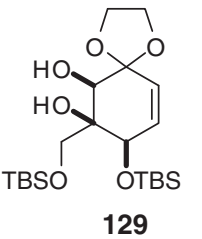

1) $(\mathrm{COCl})_{2} / \mathrm{DMSO}$ $\mathrm{Et}_{3} \mathrm{~N} / \mathrm{CH}_{2} \mathrm{Cl}_{2}$

2) TESOTf / pyridine $65 \%$ (2 steps)

129<smiles>CCOCC1(COC(C)(C)C)C(=O)C2(C=CC1[Se]OC(C)(C)C)OCCO2</smiles>

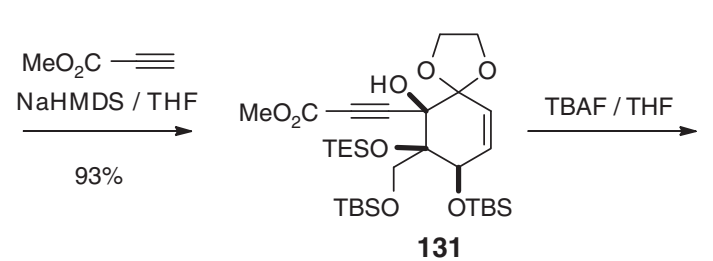

131

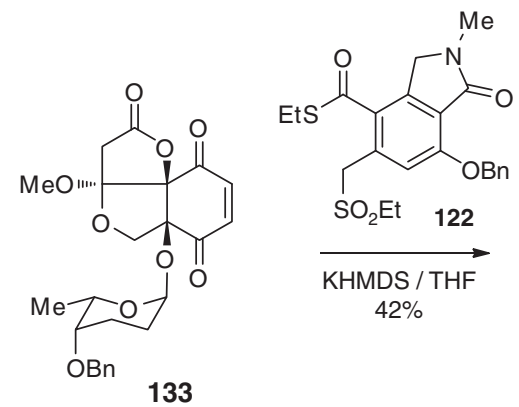<smiles>CC(=O)C=C1OCC2(O)C(O)C=CC3(OCCO3)C2O1</smiles>

132

\section{1) $\mathrm{AcCl} / \mathrm{MeOH}$ 2) $\underset{\mathrm{IBX} /\left(\mathrm{CH}_{2} \mathrm{Cl}\right)_{2}}{54 \%(3 \text { steps })}$}<smiles>CO[C@]12CC(=O)O[C@]3(C(=O)C=CC(=O)C3(O)O)[C@@H]1O2</smiles>

(士)-121

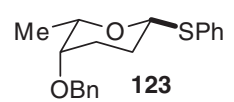

2-cyclohexen-1-one AgOTf

MS-4A $\mathrm{CH}_{2} \mathrm{Cl}_{2}$ $-40^{\circ} \mathrm{C}$ to rt, $11 \mathrm{~h}$

(Resolution)<smiles>CO[C@@]12CO[C@]3(OC4CC(C)C(OCc5ccccc5)C4)C(=O)c4cc5cc(OCc6ccccc6)c6c(c5c(O)c4C(=O)[C@@]13OC(=O)C2)CN(C)C6=O</smiles>

134

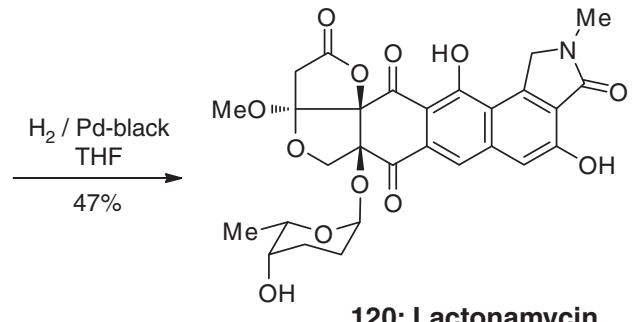

120: Lactonamycin

Figure 17 Total synthesis of lactonamycin.

stereospecific introduction of the hydroxy group at C12a to give a furan derivative 145 . The cycloaddition with 140 in the presence of 2,6-di-tert-butyl-4-methylphenol proceeded from the $\beta$-face of 139, regio- and stereoselectively as expected. This highly-stereoselective reaction gave a labile adduct, which upon acidic oxidation, was transformed to the $\alpha, \beta$-unsaturated ketone 141. The tandem Michael-Dieckmann type reaction of 141 with the isobenzofuranone 142 gave the tetracyclic compound 143.66 One of the key problems of this synthesis was the stereoselective introduction of a hydroxyl group at C12a. Manipulation of the protective groups of 143 gave the diol 144, which was adequate to oxidate the right wing. The primary alcohol of 144 participated in the bromination of C1-12a olefin to give the desired $\mathbf{1 4 5}$. Treatment of $\mathbf{1 4 5}$ with a mixture of pyridinium chlorochromate and pyridinium dichromate in dichloromethane, followed by purification with silica gel, afforded the aldehyde 146 in $61 \%$ yield. This transformation realized the concurrent oxidation of primary and secondary alcohols accompanied by introduction of the C12a hydroxyl group. The resulting 146 was converted to the nitrile 147 by a newly-developed method using hydroxylamine followed by dehydration with $1,1^{\prime}$ carbonyldiimidazole. The nitrile 147 was transformed through 148 and the perhydroxide 149 into (-)-tetracycline (8), which was identical with natural (-)-tetracycline in all respects, thus completing the first total synthesis. Our tetracycline synthesis was the first to be accomplished, some 50 years after its structure had been determined. ${ }^{48}$

The first total synthesis of a pseudo-dimer of tetracycline, hibarimicinone

Hibarimicins, isolated from the culture broth of Microbispora rosea subsp. hibaria, have been known to possess v-Src tyrosine kinase inhibitory activity and differentiation inducing activity of HL-60 cells. ${ }^{67,68}$ Among them, hibarimicinone (150) has the most potent activity of $\mathrm{v}$-Src tyrosine kinase inhibition without differentiation inducing activity. The structure of hibarimicinone (150) has been disclosed to be a fascinating pseudo-dimer of tetracycline, which includes 13 stereogenic centers as well as the axial chirality (Figure 19). On this final chapter, the author presents the first total synthesis of hibarimicinone (150). ${ }^{69,70}$

The strategy chosen to construct the eight-ring skeleton was a double Michael-Dieckmann type cyclization ${ }^{2-6,64,71}$ using the chiral biaryl thiolactone 152 (DE segment) and the chiral decalin 151 

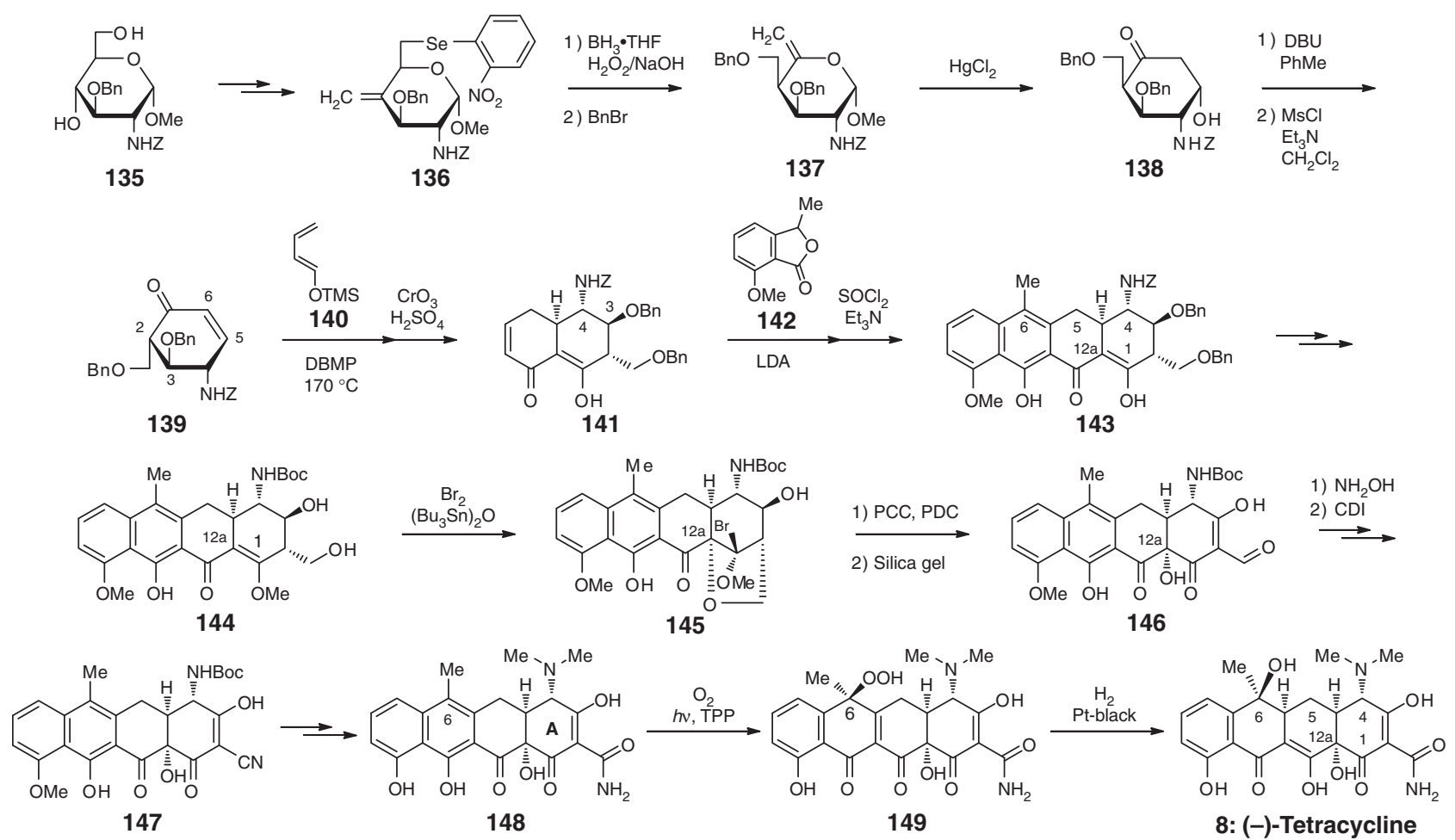

Figure 18 Total synthesis of natural (-)-tetracycline.

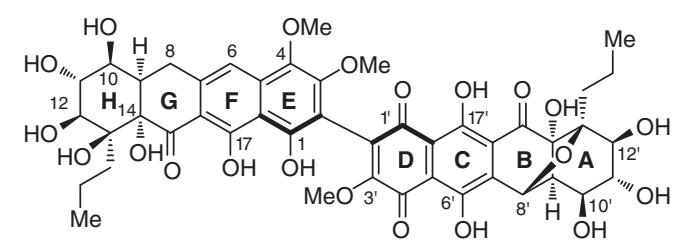

150:Hibarimicinone

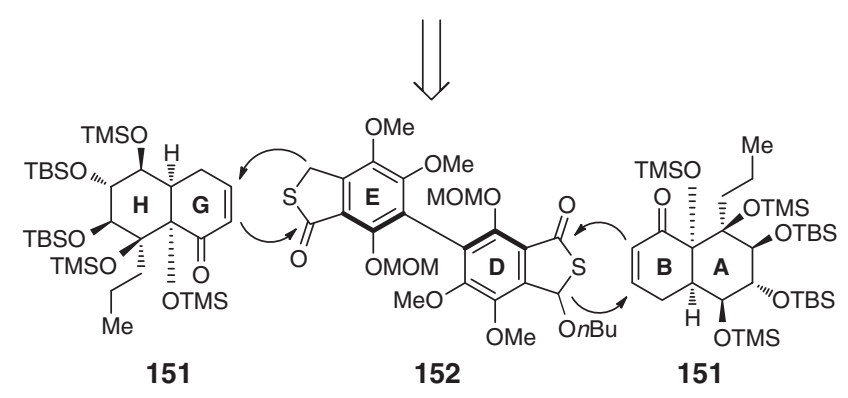

Figure 19 Retrosynthesis of hibarimicinone.

(AB and GH segments) in Figure 19. Difference of the oxidation stage of thiolactones in biaryl $\mathbf{1 5 2}$ should reflect the oxidation stage of CD and EF rings. At first, the synthesis of decalin 151, the common structure of $\mathrm{AB}$ and $\mathrm{GH}$ rings, started from the enone $157,{ }^{72-74}$ which was derived from D-arabinose 153 through $\mathrm{D}$-arabinonic acid $\gamma$ lactone 154 (Figure 20). This methodology had already been developed for synthesis of progesterone receptor ligands, PF1092s in our laboratories, ${ }^{72}$ and applied to the total syntheses of pyralomicin $1 c,{ }^{73}$ valienamine and validamine. ${ }^{74}$ The phenylsulfonate 155 was silylated to the opened chain enolate 156 in one step by simultaneous formation of an enol silyl ether and an $O$-silyl secondary alcohol. The
$\mathrm{SnCl}_{4}$-promoted aldol condensation of $\mathbf{1 5 6}$ resulted in the formation of the key enone 157. Diels-Alder reaction proceeded stereoselectively to give adduct $\mathbf{1 5 8}$, which possessed the desired $9 R$ configuration (hibarimicinone numbering). Jones oxidation, converting the allyl trimethysilyl ether to the enone, and the subsequent reduction with $\mathrm{SmI}_{2}$ to remove the sulfone gave the Sm(III) enolate 159, which was oxidized to provide stereoselectively the tertiary alcohol $\mathbf{1 6 0}$. The $\mathrm{C} 10 \alpha$-alcohol 160 was converted into the $\beta$-alcohol 161 through regio- and stereoselective de-O-silylation, oxidation and reduction. Protection of the tertiary alcohol of $\mathbf{1 6 1}$ accompanied with formation of the dienyl silyl ether $\mathbf{1 6 2}$ as desired in the right ring, and the subsequent Grignard reaction introduced an allyl group in a stereoselective manner to give the tertiary alcohol $\mathbf{1 6 3}$. After silylation of the tertiary alcohol, treatment of the dienyl silyl ether with DBU in hot toluene in the presence of $i-\mathrm{PrOH}$ promoted the regioselective de-silylation, followed by hydrogenation of the exo olefin to yield the enone decalin segment 151 corresponding to the $\mathrm{AB}$ and $\mathrm{GH}$ segments (Figure 20).

For constructing the DE segment, the chiral biaryl thiolactone $\mathbf{1 5 2}$ was obtained as shown in Figure 21 . The commercially available carboxylic acid 164 was converted into 165 through ortho-lithiationmethylation of the corresponding amide and regioselective de-Omethylation. Phenol 165 was subjected to oxidative dimerization by using silver trifluoroacetate, and the resulting bisphenol was protected as benzoate 166. Two benzylic positions of 166 were brominated and the sequential substitution with thioacetate ion and methanolysis produced the thiolactones $\mathbf{1 6 7}$ with free phenols. The racemic biaryl 167 was converted to the diastereo-mixture of mono-camphanate, which was resolved by column chromatography and subsequent crystallization to give the optically pure $168\left(\mathrm{R}^{\star}=(-)\right.$-camphanyl group) in good yield. The desired isomer 168 was converted into symmetrically protected 169 . Mono-bromination of 169 and 

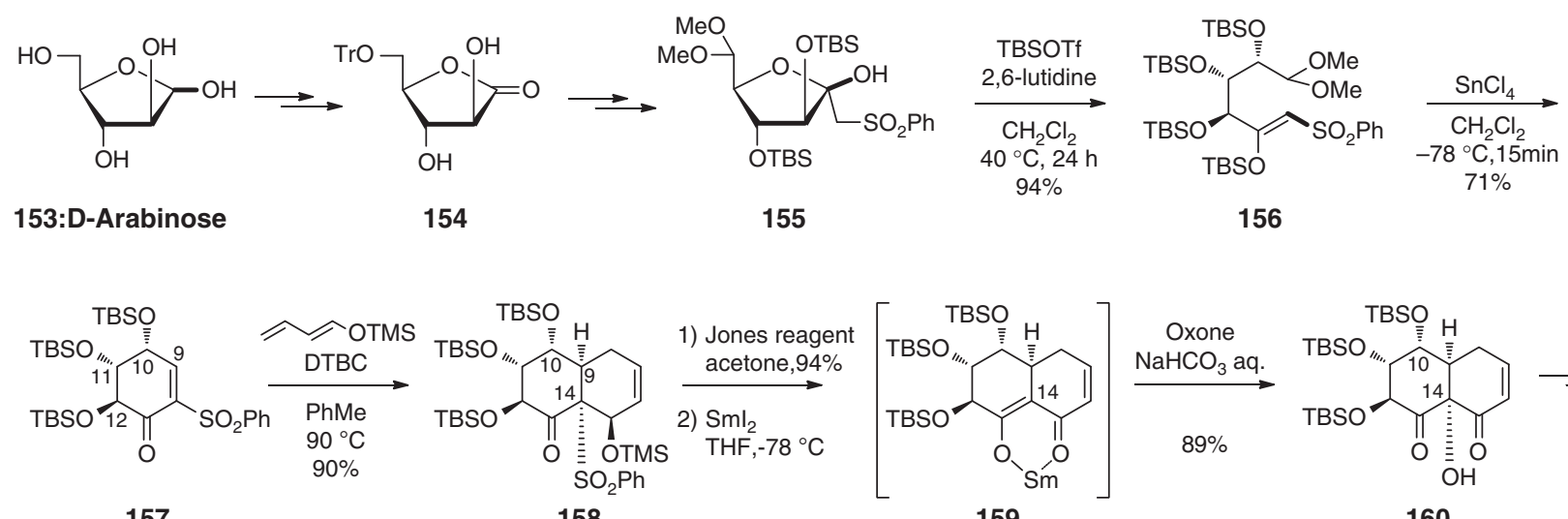

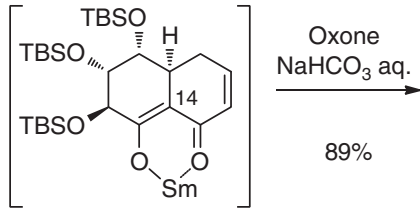

159

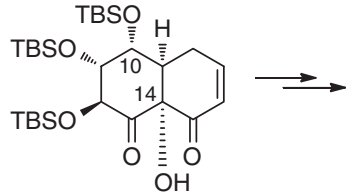

160

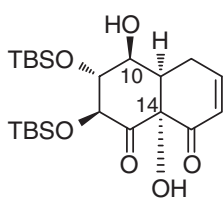

161

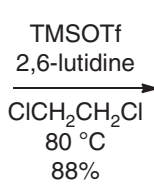

$8 \%$

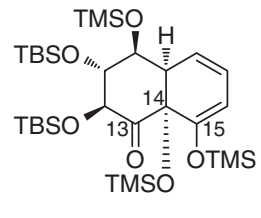

162

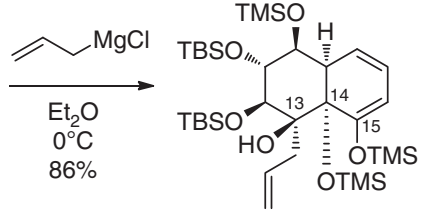

163
1) TMSOTf

2,6-Iutidine $\mathrm{ClCH}_{2} \mathrm{CH}_{2} \mathrm{Cl}$

2) $\mathrm{DBU} / i-\mathrm{PrOH}$ $\mathrm{PhMe}$

3) $\mathrm{H}_{2} / \mathrm{Pd}-\mathrm{C}$ $\mathrm{PhMe}$ $72 \%$ (3steps)

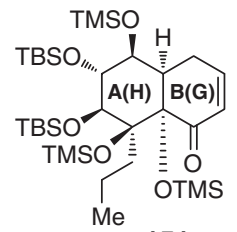

151

Figure 20 Synthesis of $A B$ and $G H$ segments of hibarimicinone.<smiles>COc1cc(OC)c(C(=O)O)cc1OC</smiles>

164<smiles>COC(=O)c1c(O)cc(OC)c(OC)c1OC</smiles>

165

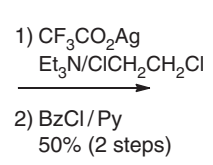
$50 \%$ (2 steps)

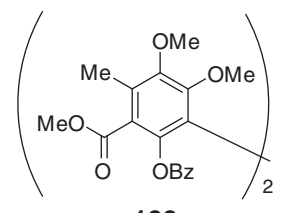

166

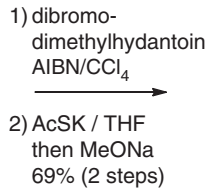

69\% (2 steps)

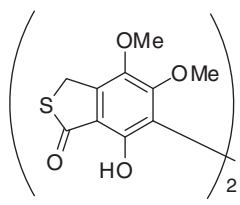

167

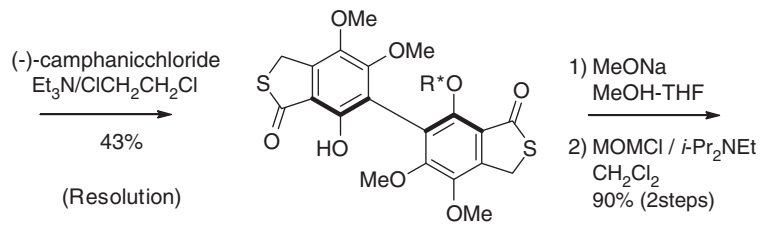

168

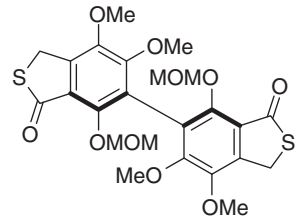

169

(1)

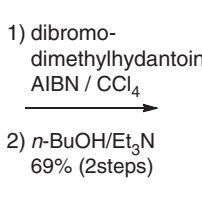

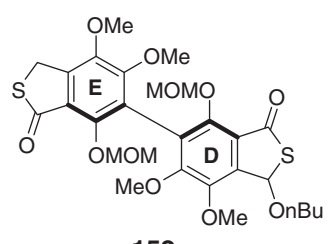

152

Figure 21 Synthesis of DE segment of hibarimicinone.

substitution with $n$-butanol were performed in one pot to give the chiral biaryl 152.

With both segments 151 and 152 in hand, their conversion to an eight-ring skeleton in a one-pot reaction was explored (Figure 22). In preliminary studies, we found that Michael-Dieckmann type cyclization using the non-substituted benzothiolactone (the left ring type of 152) proceeded in THF, while the cyclization with the alkoxybenzothiolactone (the right ring type) was promoted in toluene. Pyridine suppressed generation of polymerized products. Therefore, the enone 151 and bis-thiolactone 152 were treated with base in the mixed solvent including THF, toluene and pyridine to promote double Michael-Dieckmann type cyclization to give the eight rings, and the resulting thiolates were methylated to provide the enol form $\mathbf{1 7 0}$ and its labile keto form in $\mathrm{G}$ ring, the latter of which was smoothly converted into the enol $\mathbf{1 7 0}$ in the presence of LiCl. Hydrolysis of semithioacetal was performed with $\mathrm{AgNO}_{3}$, and the subsequent treatment with $\mathrm{DBU}$ gave the hydroquinone at the $\mathrm{C}$ ring, followed by oxidation of the $\mathrm{C}$ ring and aromatization of $\mathrm{F}$ ring, including elimination of thioether and tautomerization to afford 171 in one pot. The ether bond crossing the $\mathrm{AB}$ rings was formed with excess amounts of LiI by enolization at the $\mathrm{BC}$ rings, followed by conjugate addition to the enone $\mathbf{1 7 2}$. The simultaneous de-O-methoxymethylation gave the free phenols ( $\mathrm{D}$ and $\mathrm{E}$ rings) in 173. The resulting 173 was immediately oxidized to the quinone $\mathbf{1 7 4}$. Finally, de-O-silylation as well as de-O-methylation and tautomerization at the $\mathrm{CD}$ rings were achieved under the acidic conditions to give hibarimicinone (150), 


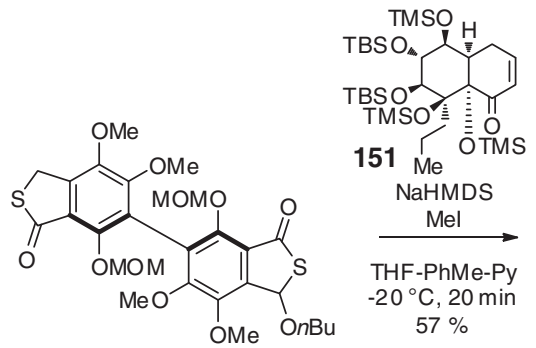

152

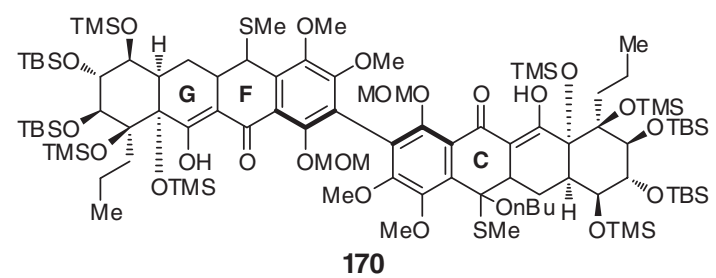

1) $\mathrm{AgNO}_{3}$

PhMe-acetone- $\mathrm{H}_{2} \mathrm{O}$

2) $\mathrm{DBU}, \mathrm{PhMe}$

3) $\mathrm{Ag}_{2} \mathrm{CO}_{3}$

PhMe-acetone- $\mathrm{H}_{2} \mathrm{O}$

then $\mathrm{Mel}$

$63 \%$ (3 steps)

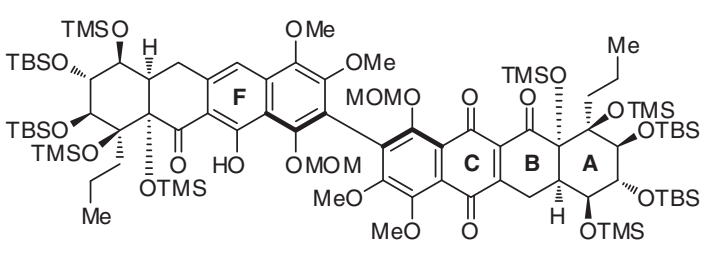

171

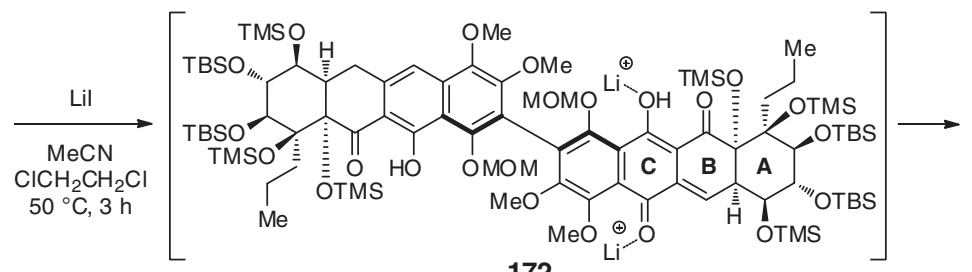

172

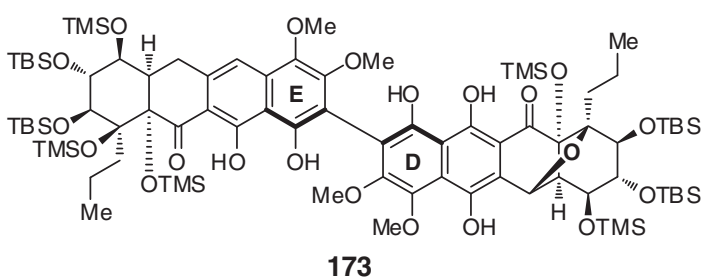

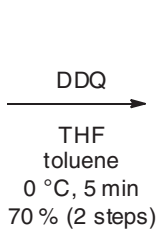
$70 \%$ (2 steps)

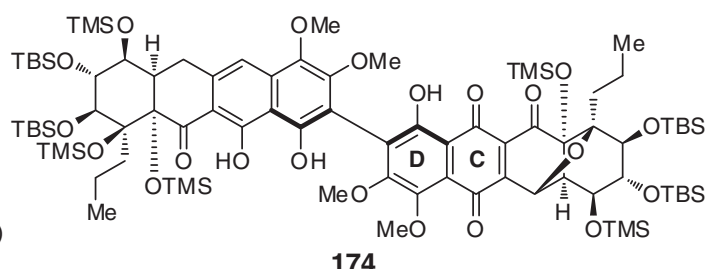

174

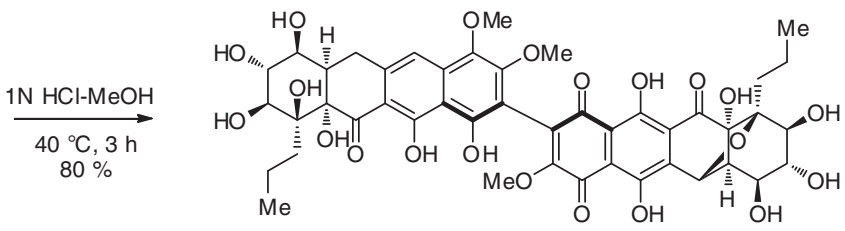

150:Hibarimicinone

Figure 22 Total synthesis of hibarimicinone.

completing the first total synthesis. ${ }^{69,70}$ This is the 102nd accomplishment of total syntheses by the author.

\section{CONCLUSION}

The total synthesis of the big four antibiotics as well as the related antibiotics are reviewed. Most of the total syntheses that have been completed in our laboratories have been the first ever accomplished. Establishment of the total syntheses by use of carbohydrates as chiral sources created a comprehensive method to investigate a variety of bioactive natural products. The achievement of successful results in research is, of course, of prime importance. Yet, before undertaking research, it is essential that the objectives of the research are clearly understood and defined. Hence, it may be no exaggeration to say that the selection of target molecules decides, above all, the value of the research itself, particularly with respect to bioactive natural product synthesis. In essence, the author believes that the most important factor is to make the utmost effort towards realizing one's goals, that is, to synthesize a target molecule by one's own concepts and strategies. However, through completion of such enterprise and skill, one can certainly produce the 'art', as mentioned in the introduction, which becomes manifest in the reactions and/or products.

\section{ACKNOWLEDGEMENTS}

The author would like to thank all of his co-workers whose names appear in the references for their intellectual contribution and hard work, and he is also grateful for financial support from the Research Institute for Science and Engineering, Waseda University and the Consolidated Research Institute for Advanced Science and Medical Care, the Global COE program 'Center for Practical Chemical Wisdom', and Scientific Research on Priority Area 'Creation of Biologically Functional Molecules' from the Ministry of Education, Culture, Sports, Science and Technology.

1 Gabor, L. \& Ohno, M. Recent Progress in the Chemical Synthesis of Antibiotics (Springer-Verlag, Heidelberg, 1990).

2 Tatsuta, K. Total syntheses of useful bioactive compounds. Adv. Synth. Catal. 2001, 143-159 (2001).

3 Tatsuta, K. Significance of total synthesis of bioactive compounds. Curr. Org. Chem. 2001, 207-231 (2001).

4 Tatsuta, K. \& Hosokawa, S. Total synthesis of selected bioactive natural products: illustration of strategy and design. Chem. Rev. 105, 4707-4729 (2005).

5 Tatsuta, K. \& Hosokawa, S. Total synthesis of polyketide-derived bioactive natural products. Chem Rec. 6, 217-233 (2006).

6 Tatsuta, K. Total synthesis and development of bioactive natural products. Proc. Jpn. Acad., Ser. B. 84, 87-106 (2008).

7 Tatsuta, K., Nakagawa, A., Maniwa, S., Amemiya, Y. \& Kinoshita, M. Stereospecific total synthesis and absolute configuration of a macrocyclic lactone antibiotic, A26771B. Tetrahedron Lett. 21, 1479-1482 (1980). 
8 Tatsuta, K., Tanaka, A., Fujimoto, K., Kinoshita, M. \& Umezawa, S. Synthesis of carbomycin B. Introduction of the amino disaccharide onto the 16-membered-ring aglycone. J. Am. Chem. Soc. 99, 5826-5827 (1977).

9 Tatsuta, K., Amemiya, Y., Maniwa, S. \& Kinoshita, M. Total synthesis of carbomycin B and josamycin (leucomycin A3). Tetrahedron Lett. 21, 2837-2840 (1980).

10 Tatsuta, K., Amemiya, Y., Kanemura, Y. \& Kinoshita, M. Synthesis of tylonolide, an aglycone of tylosin. Tetrahedron Lett. 22, 3997-4000 (1981).

11 Tatsuta, K., Amemiya, Y., Kanemura, Y., Takahashi, H. \& Kinoshita, M. Total synthesis of tylosin. Tetrahedron Lett. 23, 3375-3378 (1982).

12 Corey, E. J. \& Nicolaou, K. C. Efficient and mild lactonization method for the synthesis of macrolides. J. Am. Chem. Soc. 96, 5614-5616 (1974).

13 Tatsuta, K., Fujimoto, K., Kinoshita, M. \& Umezawa, S. A novel synthesis of 2-deoxy- $\alpha$ glycosides. Carbohydr. Res. 54, 85-104 (1977).

14 Okamoto, R. et al. New macrolide antibiotics produced by mutants from Streptomyces fradiae NRRL 2702. J. Antibiot. 35, 921-924 (1982).

15 Tatsuta, K., Kobayashi, Y., Gunji, H. \& Masuda, H. Synthesis of oleandomycin through the intact aglycone, oleandolide. Tetrahedron Lett. 29, 3975-3978 (1988).

16 Tatsuta, K., Ishiyama, T., Tajima, S., Koguchi, Y. \& Gunji, H. The total synthesis of oleandomycin. Tetrahedron Lett. 31, 709-712 (1990).

17 Toshima, K. et al. Application of highly stereocontrolled glycosidations employing 2,6 anhydro-2-thio sugars to the syntheses of erythromycin A and olivomycin A trisaccharide. J. Am. Chem. Soc. 117, 3717-3727 (1995).

18 Toshima, K. \& Tatsuta, K. Recent progress in O-glycosylation methods and its application to natural product synthesis. Chem. Rev. 93, 1503-1531 (1993).

19 Toshima, K. et al. Novel glycosidation method using 2,6-anhydro-2-thio sugars for stereocontrolled synthesis of 2,6-dideoxy- $\alpha$ - and $-\beta$-glycosides. J. Am. Chem. Soc 116, 9042-9051 (1994).

20 Igarashi, M. et al. Tubelactomicin A, a novel 16-membered lactone antibiotic, from Nocardia sp. I. Taxonomy, production, isolation and biological properties. J. Antibiot. 53, 1096-1107 (2000).

21 Hosokawa, S., Seki, M., Fukuda, H. \& Tatsuta, K. Total synthesis of an antitubercular lactone antibiotic, (+)-tubelactomicin A. Tetrahedron Lett. 47, 2439-2442 (2006).

22 Motozaki, T. et al. Total synthesis of $(+)$-tubelactomicin A. 2. Synthesis of the upperhalf segment and completion of the total synthesis. Org. Lett. 7, 2265-2267 (2005).

23 Miyaura, N. \& Suzuki, A. Palladium-catalyzed cross-coupling reactions of organoboron compounds. Chem. Rev. 95, 2457-2483 (1995).

24 Shiina, I., Kubota, M. \& Ibuka, R. A novel and efficient macrolactonization of $\omega$ hydroxycarboxylic acids using 2-methyl-6-nitrobenzoic anhydride (MNBA). Tetrahedron Lett. 43, 7535-7539 (2002).

25 Shindo, K., lijima, H. \& Kawai, H. Studies on cochleamycins, novel antitumor antibiotics II. Physico-chemical properties and structure determination. J. Antibiot. 49, 244-248 (1996)

26 Tatsuta, K., Narazaki, F., Kashiki, N., Yamamoto, J. \& Nakano, S. The first total synthesis of cochleamycin A and determination of the absolute structure. J. Antibiot. 56, 584-590 (2003)

27 Dineen, T. A. \& Roush, W. R. Total synthesis of cochleamycin A. Org. Lett. 6, 2043-2046 (2004).

28 Tatsuta, K. \& Hosokawa, S. Total synthesis of complicated natural products from simple carbohydrates. Curr. Org. Chem. (2008) 207-231 (2008).

29 Kita, Y., Maeda, H., Omori, K., Okuno, T. \& Tamura, Y. J. Novel efficient synthesis of 1 ethoxyvinyl esters using ruthenium catalysts and their use in acylation of amines and alcohols: synthesis of hydrophilic $3^{\prime}-\mathrm{N}$-acylated oxaunomycin derivatives. Chem. Soc. Perkin Trans. 1, 2999-3005 (1993).

30 Tatsuta, K., Suzuki, Y., Furuyama, A. \& Ikegami, H. The first total synthesis of a tetracyclic Antibiotic, (-)-tetrodecamycin. Tetrahedron Lett. 47, 3595-3598 (2006).

31 Umezawa, S., Tatsuta, K. \& Tsuchiya, T. Studies of aminosugars. XII. The absolute structure of kanamycin as determined by a copper complex method. Bull. Chem. Soc. Jpn. 39, 1244-1248 (1966).

32 Umezawa, S., Koto, S. \& Tatsuta, K. The total synthesis of kanamycin B. J. Antibiot. 21, 424-425 (1968) and references cited therein.

33 O'Connor, S., Lam, L. K. T., Jones, N. D. \& Chaney, M. O. Apramycin, a unique aminocyclitol antibiotic. J. Org. Chem. 41, 2087-2092 (1976).

34 Awata, N. et al. Saccharocin, a new aminoglycoside antibiotic fermentation, isolation, characterization and structural study. J. Antibiot. 36, 651-656 (1983).

35 Tatsuta, K. et al. Total synthesis of aminoglycoside antibiotics, apramycin and saccharocin (KA-5685). Bull. Chem. Soc. Jpn. 57, 529-538 (1984).

36 Mukaiyama, T., Murai, Y. \& Shoda, S. An efficient method for glucosylation of hydroxy compounds using glucopyranosyl fluoride. Chem. Lett. 1981, 431-432 (1981).

37 Kahan, J. S. et al. Thienamycin, a new $\beta$-lactam antibiotic I. Discovery, taxonomy, isolation and physical properties. J. Antibiot. 32, 1-12 (1979).

38 Berks, A. H. Preparations of two pivotal intermediates for the synthesis of 1 - $\beta$-methy carbapenem antibiotics. Tetrahedron. 52, 331-375 (1996).

39 Salzmann, T. N., Ratcliffe, R. W., Christensen, B. G. \& Bouffard, F. A. A stereocontrolled synthesis of (+)-thienamycin. J. Am. Chem. Soc. 102, 6161-6163 (1980).

40 Reider, P. J. \& Grabowski, E. J. J. Total synthesis of thienamycin: a new approach from aspartic acid. Tetrahedron Lett. 23, 2293-2296 (1982).

41 Tatsuta, K., Takahashi, M., Tanaka, N. \& Chikauchi, K. Novel synthesis of (+)-4acetoxy-3-hydroxyethyl-2-azetidinone from carbohydrate. Total synthesis of $(+)$-thienamycin. J. Antibiot. 53, 1231-1234 (2000).
42 Kanai, T., Morita, Y., Shinohara, H., Kai, Y. \& Ogura, K. Reaction of insoluble 2-(5amino-1,2,4-thiadiazol-3-yl)-2-((fluoromethoxy)imino)acetic acid with insoluble $\mathrm{PCl}_{5}$ in $\mathrm{CH}_{2} \mathrm{Cl}$. Chem. Express. 7, 805-806 (1992).

43 Tatsuta, K., Miura, S., Gunji, H., Tamai, T. \& Inagaki, T. A practical preparation of ( $Z$ ) 2-(5-amino-1,2,4-thiadiazol-3-yl)-2-(methoxyimino)acetic acid. Tetrahedron Lett. 34 6423-6426 (1993)

44 Tatsuta, K. et al. Practical preparation of (Z)-2-(5-amino-1,2,4-thiadiazol-3-yl)-2 methoxy-iminoacetic acid: a side-chain of the fourth generation of cephem antibiotics. Bull. Chem. Soc. Jpn. 67, 1701-1707 (1994).

45 Miyake, A. et al. Studies on condensed-heterocyclic azolium cephalosporins. J. Antibiot. 45, 709-720 (1992).

46 Woodward, R. B. The total synthesis of a tetracycline. Pure Appl. Chem. 6, 561-574 (1963).

47 Stork, G., La Clair, J. J., Spargo, P., Nargund, R. P. \& Totah, N. Stereocontrolled synthesis of ( \pm )-12a-deoxytetracycline. J. Am. Chem. Soc. 118, 5304-5305 (1996) and references cited therein.

48 Tatsuta, K., Yoshimoto, T., Gunji, H., Okado, Y. \& Takahashi, M. The first total synthesis of natural (-)-tetracycline. Chem. Lett. 2000, 646-647 (2000).

49 Charest, M. G., Lerner, C. D., Brubaker, J. D., Siegel, D. R. \& Myers, A. G. A convergent enantioselective route to structurally diverse 6-deoxytetracycline antibiotics. Science. 308, 395-396 (2005).

50 Ōmura, S. et al. Nanaomycins A and B, new antibiotics produced by a strain of Streptomyces. J. Antibiot. 27, 363-365 (1974).

51 Ōmura, S., Tanaka, H., Okada, Y. \& Marumo, H. Isolation and structure of nanaomycin D, an enantiomer of the antibiotic kalafungin. J. Chem. Soc., Chem. Commun. (1976) 320-321 (1976).

52 Tatsuta, K., Akimoto, K., Annaka, M., Ohno, Y. \& Kinoshita, M. Enantiodivergent total syntheses of ( - -)-nanaomycin D and its enantiomer, (+)-kalafungin. J. Antibiot. 38 680-682 (1985)

53 Tatsuta, K., Akimoto, K., Annaka, M., Ohno, Y. \& Kinoshita, M. Enantiodivergent total syntheses of nanaomycins and their enantiomers, kalafungins. Bull. Chem. Soc. Jpn. 58, 1699-1706 (1985)

54 Tatsuta, K., Ozeki, H., Yamaguchi, M., Tanaka, M. \& Okui, T. Enantioselective tota synthesis of medermycin (lactoquinomycin). Tetrahedron Lett. 31, 5495-5498 (1990).

55 Tsukamoto, M. et al. New cytotoxic agents, BE-52440A and B, produced by a Streptomycete. J. Antibiot. 53, 687-693 (2000)

56 Tatsuta, K., Suzuki, Y., Toriumi, T., Furuya, Y. \& Hosakawa, S. The first total synthesis and structural determination of (+)-BE-52440A. Tetrahedron Lett. 48, 8018-8021 (2007).

57 Iwai, Y. et al. OM-173, new nanaomycin-type antibiotics produced by a strain of Streptomyces. J. Antibiot. 36, 1268-1274 (1983).

58 Kasai, M. et al. Structure of nanaomycin E, a new nanaomycin. J. Antibiot. 32, 442-445 (1979).

59 Tatsuta, K. Hirabayashi, T., Kojima, M. Suzuki, Y \& Ogura, T. The first total synthesis of a pyranonaphthoquinone antitumor, BE-54238B. J. Antibiot. 57, 291-297 (2004).

60 Matsumoto, N. et al. Lactonamycin, a new antimicrobiral antibiotic produced by Streptomyces rishiriensis. J. Antibiot. 49, 953-954 (1996).

61 Matsumoto, N. et al. Lactonamycin, a new antimicrobiral antibiotic produced by Streptomyces rishiriensis MJ773-884. II. Structure determination. J. Antibiot. 52, 276-280 (1999)

62 Parsons, P. J., Waters, A. J., Walter, D. S. \& Board, J. A new route to highly functionalized heterocyclic rings. J. Org. Chem. 72, 1395-1398 (2007).

63 Siu, T., Cox, C. D. \& Danishefsky, S. J. Total synthesis of lactonamycinone. Angew. Chem. Int. Ed. 42, 5629-5634 (2003).

64 Tatsuta, K., Tanaka, H., Tsukagoshi, H., Kashima, T. \& Hosokawa, S. The first total synthesis of lactonamycin, a hexacyclic antitumor antibiotic. Tetrahedron Lett. 51, 5546-5549 (2010).

65 Tatsuta, K. \& Hosokawa, S. Total synthesis of bioactive natural products from carbohydrates. Sci. Tech. Adv. Mater. 7, 397-410 (2006).

66 Tatsuta, K., Yamazaki, T., Mase, T. \& Yoshimoto, T. The first total synthesis of a bioxanthracene (-)-ES-242-4, an $\mathrm{N}$-methyl-D-aspartate receptor antagonist. Tetrahedron Lett. 39, 1771-1772 (1998).

67 Kajiura, T. et al. Biosynthesis of hibarimicins II. Elucidation of biosynthetic pathway by cosynthesis using blocked mutants. J. Antibiot. 55, 53-60 (2002) and references cited therein.

68 Igarashi, Y. et al. Biosynthesis of hibarimicins III. Structures of new hibarimicin-related metabolites produced by block mutants. J. Antibiot. 55, 61-70 (2002).

69 Tatsuta, K. et al. The first total synthesis of hibarimicinone, a potent v-Src tyrosine kinase inhibitor. Tetrahedron Lett. 53, 422-425 (2012).

70 Tatsuta, K. Recent progress in total synthesis of bioactive natural products. Abstracts of Papers of The 2nd Tishler-Ōmura Symposium, Tokyo (2011)

71 Tatsuta, K. et al. The first total synthesis and structural determination of antibiotics K1115B1s (alnumycins). Tetrahedron Lett. 52, 983-986 (2011).

72 Tatsuta, K. et al. Total synthesis of progesterone receptor ligands, (-)-PF1092A, B and C. Tetrahedron Lett. 38, 1439-1442 (1997)

73 Tatsuta, K., Takahashi, M. \& Tanaka, N. The first total synthesis of pyralomicin 1c. J. Antibiot. 53, 88-91 (2000).

74 Tatsuta, K., Mukai, H. \& Takahashi, M. Novel synthesis of natural pseudo-aminosugars, (+)-valienamine and (+)-validamine. J. Antibiot. 53, 430-435 (2000). 
Structures of the 102 Synthesized Compounds

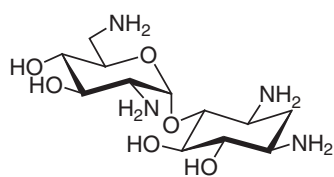

1: Neamine (1967)

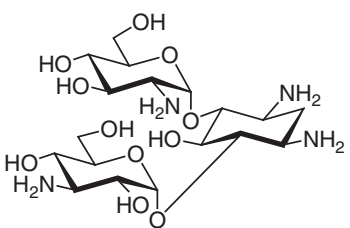

5: Kanamycin C

(1968)

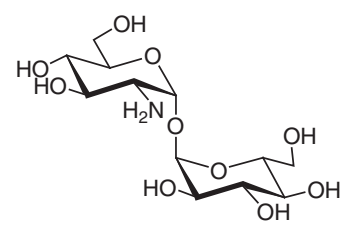

2: Trehalosamine (1967)

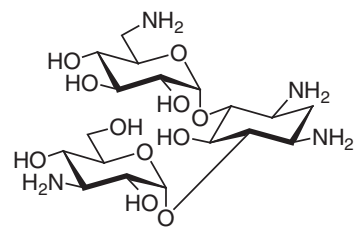

3: Kanamycin A (1968)

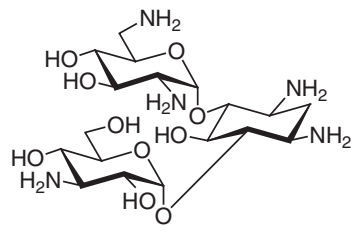

4: Kanamycin B (1968)

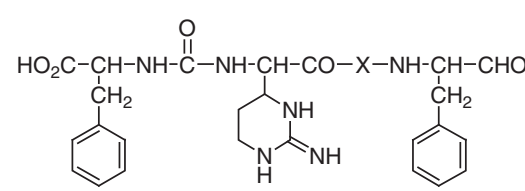

6: Chymostatin A: $X=L-L e u$ (1973)<smiles>[X]OC(=O)C(CC1CCNC(=N)N1)NC(=O)N[C@H](Cc1ccccc1)C(=O)O</smiles>

7: Chymostatin B: $X=L-V a l$ (1973)

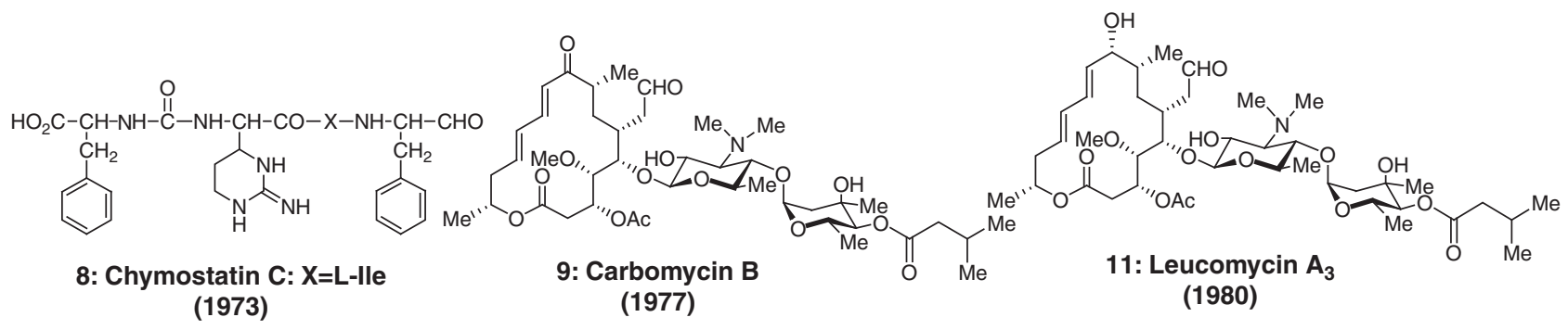<smiles>C=C1C[C@@H]2C[C@H]3C(CC12)C[C@H]1CC(C)(C)C[C@@H]13</smiles>

10: Hirsutene (1979)

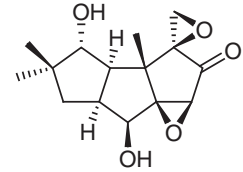

12: Coriolin (1980)

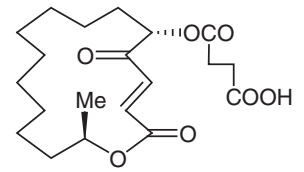

13: A26771B (1980)

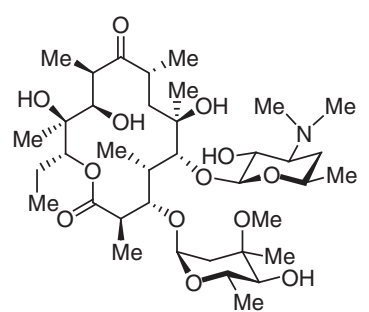

14: Erythromycin A (1981)

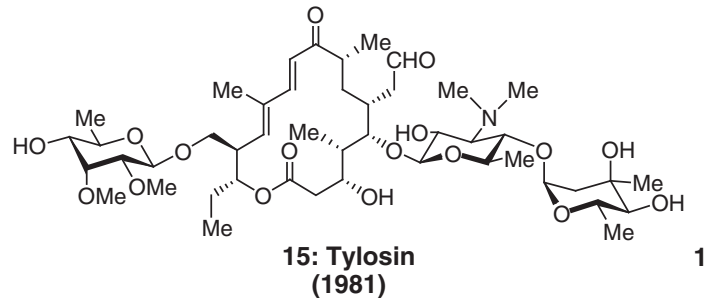<smiles>OCC1CCN2CCCC12</smiles>

16: Isoretronecanol (1982)

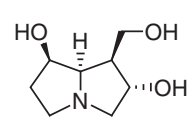

17: Rosmarinecine (1982)

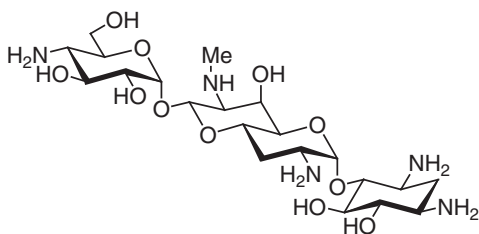

18: Apramycin (1983) 
Structures of the 102 Synthesized Compounds (continued)

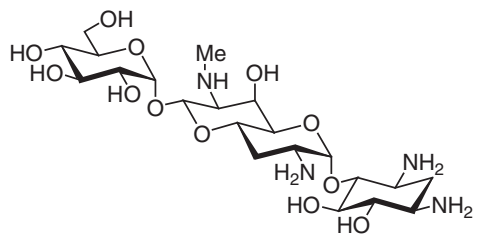

19: Saccharocin (1983)

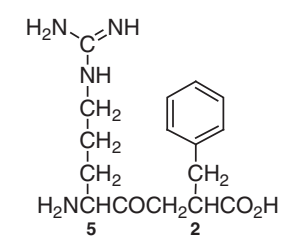

20: Arphamenine A $(2 R, 5 S)$

21: Epi-arphamenine A $(2 S, 5 S)$

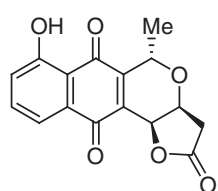

22: Nanaomycin D (1985)

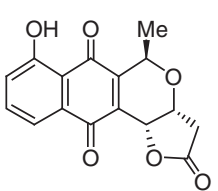

23: Kalafungin (1985)

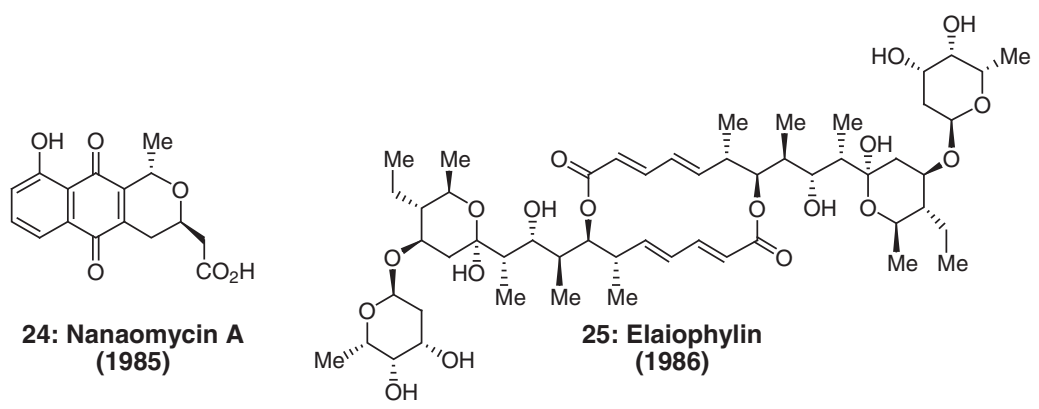<smiles>O=CNC=Cc1cc(O)ccc1O</smiles>

28: Erbstatin (1987)

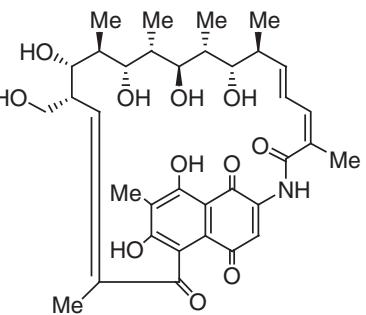

32: Rifamycin W (1990)

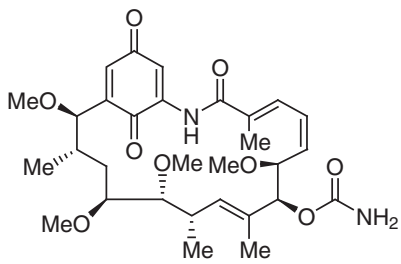

36: Herbimycin A (1991)<smiles>O=C1NC(O)CNc2[nH]cnc21</smiles>

29: Azepinomycin (1987)

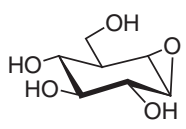

33: Cyclophellitol (1990)<smiles>CCCCC=CN(O)N[C@@H](C)C(C)=O</smiles>

37: Maniwamycin A (1993)

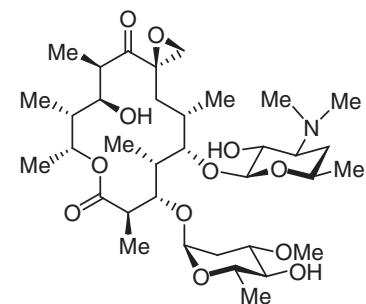

30: Oleandomycin (1988)<smiles>CC(=O)OC1(C=C(Cl)Cl)C(=O)Nc2ccccc21</smiles>

26: Indisocin (1987)<smiles>CN1C(=O)C(C=C(N)Cl)(C(=O)O)c2ccccc21</smiles>

27: N-Methylindisocin (1987)<smiles>CC/C(C)=C(\OC(=O)C(C)[C@@H](O)[C@H](Cc1cccnc1)NC(=O)[C@@H](NC(=O)c1ncccc1O)C(C)O)C(=O)O</smiles>

31: Pyridomycin (1989)

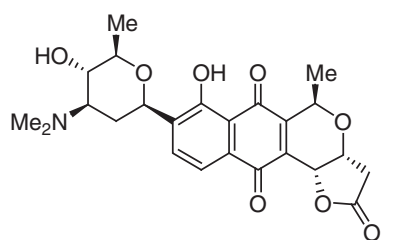

34: Medermycin (Lactoquinomycin) (1990)<smiles></smiles>

38: Maniwamycin B (1993)<smiles>CNC1=N[C@H]2[C@H](O)[C@H](O)[C@H](CO)[C@H]2O1</smiles>

35: Allosamizoline (1991)<smiles>Oc1cc(Cl)c(Cl)c(Cl)c1-n1ccc(Cl)c1Cl</smiles>

39: Neopyrrolomycin (1993) 
Structures of the 102 Synthesized Compounds (continued)<smiles>CN1C(=O)N(C)C2(CC(=O)O)N=C1N(C)N(C)C(=O)N2</smiles>

40: Pyrizinostatin (1994)<smiles></smiles>

41: AB3217-A (1994)

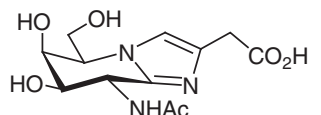

42: Nagstatin (1995)

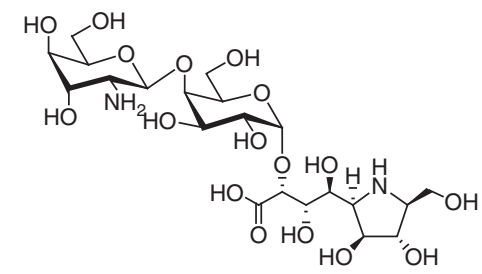

43: Gualamycin (1995)

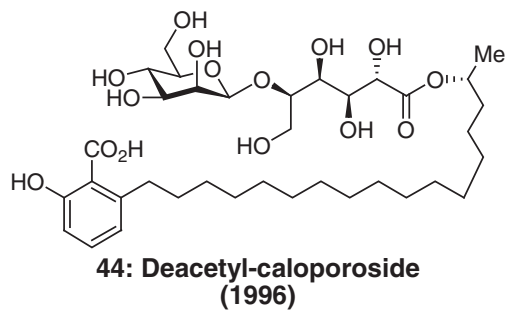

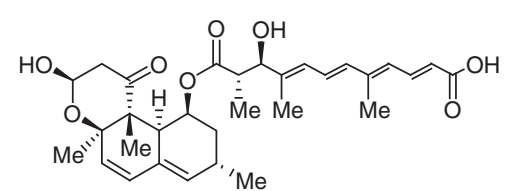

45: Calbistrin A (1997)<smiles>CC(=O)OC1C(O)C=C2C=C3OC(=O)C(C)=C3CC2(C)C1C</smiles>

46: PF1092A (1997)<smiles>CC(=O)OC1C=C2C=C3OC(=O)C(O)C3CC2(C)C(C)C1O</smiles>

47: PF1092B (1997)<smiles>CC1C(=O)OC2=C1C[C@@]1(C)C(=C2)C=C(O)[C@@H](O)C1C</smiles>

48: PF1092C (1997)<smiles>Cc1occ2c1C(=O)c1c(O)ccc(O)c1C2</smiles>

49: MS-444 (1997)<smiles>CCC(C)=CCC[C@H](O)C(C)=CC[C@@H]1C([C@@H](C)CO)=C(O)C(=O)[C@]1(C)CCC(C)C</smiles>

50: Terpestacin (1998)<smiles>O=C1C(CO)=C[C@@H](O)[C@H](O)[C@H]1O</smiles>

51: KD16-U1 (1998)<smiles>C/C=C/C(=O)OCC1=CC(O)[C@H](O)[C@H](O)C1=O</smiles>

52: Glyoxalase I Inhibitor (1998)<smiles>CC(C)C[C@H]1c2c(O)c(C=O)c(O)c(C=O)c2O[C@H](c2c(O)c(C=O)c(O)c(C=O)c2O)C1C(C)(C)C</smiles>

56: Sideroxylonal C (1999)<smiles></smiles>

53: ES-242-4 (1998)<smiles>COc1cc(OC)c2c(O)c3c(c(O)c2c1)C[C@H](O)[C@H](C)OC3</smiles>

54: ES-242-5 (1999)<smiles>CC(C)C[C@H]1c2c(O)c(C=O)c(O)c(C=O)c2O[C@H](c2c(O)c(C=O)c(O)c(C=O)c2O)[C@H]1C(C)(C)C</smiles>

55: Sideroxylonal B (1999)<smiles>Cc1cc(Cl)c(O)c2c(=O)c3cc(Cl)n([C@@H]4O[C@H](CO)[C@@H](O)[C@H](O)[C@H]4O)c3oc12</smiles>

57: Pyralomicin 2c (1999)

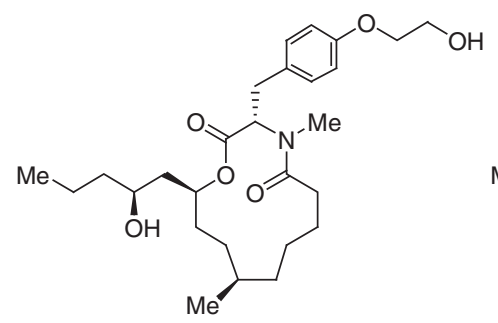

58: PF1163A (1999)<smiles>CCCCCC(CCC(C)CCCCC(=O)N1OC(=O)[C@@H](Cc2ccc(OCCO)cc2)C1=O)OC</smiles>

59: PF1163B

(1999) 
Structures of the 102 Synthesized Compounds (continued)<smiles>Cc1cc(Cl)c(O)c2c(=O)c3cc(Cl)n([C@@H]4C=C(CO)[C@@H](O)[C@H](O)[C@H]4O)c3oc12</smiles>

60: Pyralomicin 1c (2000)<smiles>Cc1ccccc1/C=C/Cc1[nH]c2ccccc2c(=O)c1C</smiles>

61: PC-3 (SF2420B) (2000)<smiles>CO[C@H]1C(O)=C(C(N)=O)C(=O)[C@@]2(O)C(O)=C3C(=O)c4c(O)cccc4[C@@](C)(O)C3C[C@H]12</smiles>

65: Tetracycline (2000)<smiles>CC(O)[C@H]1C(=O)N2C(C(=O)O)=C(SCCN)C[C@H]12</smiles>

66: Thienamycin (2000)<smiles>N[C@H]1C[C@H](CO)[C@@H](O)[C@H](O)[C@H]1O</smiles>

63: Validamine (2000)<smiles>N[C@H]1C=C(CO)[C@@H](O)[C@H](O)[C@H]1O</smiles>

64: Valienamine (2000)<smiles>CC(C)C1NC(=O)c2c1n(C)c1ccccc1c2=O</smiles>

69: Quinolactacin B (2001)<smiles>[M]C(C/C=C\CCC(O)C(=O)/C=C\CCC)OC(=O)c1c(O)cc(OC)cc1O</smiles>

70: LL-Z1640-2 (2001)<smiles>C=CC(C)(C)c1[nH]c2ccccc2c1C1=C(OC)C(=O)C(OC)=C(c2c[nH]c3c(CC=C(C)C)cccc23)C1=O</smiles>
(2001)
68: Demethylasterriquinone B1 (2001)<smiles>CCC[C@H](C(=O)c1cc(C(OC)C(C)C)c(O)c(C=O)c1O)[C@H]1C[C@H](O)[C@@]2(O)[C@H](CC)[C@H](O)O[C@H]2O1</smiles>

72: Luminacin $\mathrm{C}_{2}$ (2001)

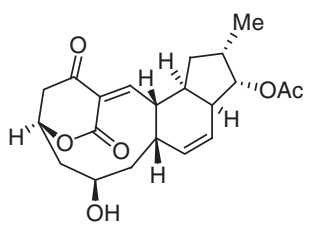

76: Cochleamycin A (2003)<smiles>COc1ccc(C=C(C#N)/C(C#N)=C/c2ccc(OC)cc2)cc1</smiles>

80: Xanthocillin $\mathrm{X}$ dimethylether (2005)

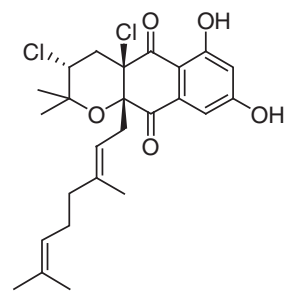

73: Napyradiomycin A1 (2002)<smiles>C=Nc1cc(N)c2c3c(cc(C(=O)C=COC)nc13)C=N2</smiles>

77: Lymphostin (2004)<smiles>CC(=Cc1ccc(O)cc1)/C(C#N)=C/c1ccc(O)cc1</smiles>

81: Xanthocillin X (2005)<smiles>Cc1c(O)cc2c(c1O)C(=O)c1c(cc3cc(O)cc(CC(=O)CC(C)O)c3c1O)C2=O</smiles>

74: UCE6 (2002)

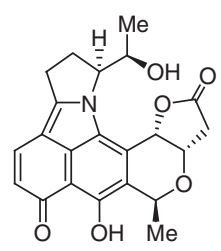

78: BE-54238B (2004)<smiles>C=C1CCC(=O)CC1(C)C(=O)C(O)C(O)C=C(C)C</smiles>

82: YM182029 (2005)

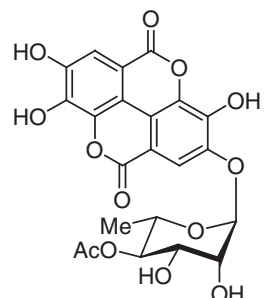

75: 4-O-(4"-O-Acetyl- $\alpha$-L-rhamnopyranosyl)-ellagic acid<smiles>CCOC</smiles>

71: Luminacin $C_{1}$ (2001)<smiles>CCC[C@H](C(=O)c1cc([C@H](OC)C(C)C)c(O)c(C=O)c1O)[C@H]1C[C@@H](O)[C@@]2(O[C@H]2CC)[C@H](O)O1</smiles> 
Structures of the 102 Synthesized Compounds (continued)

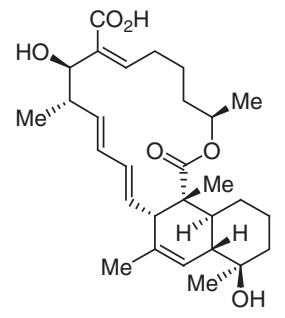

84: Tubelactomicin A (2006)

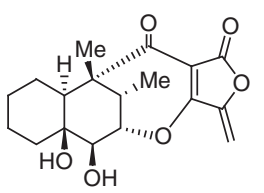

85: Tetrodecamycin (2006)

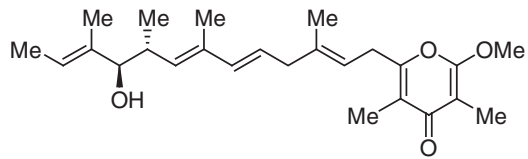

86: Actinopyrone A (2006)<smiles>CC(=CC(C)CC(C)C)c1c(C)c(=O)[nH]c2c(=O)c(=O)c(=N[N+]=[N-])c(=O)c12</smiles>

87: Lagunamycin (2006)<smiles></smiles>

88: Vinaxanthone (2007)<smiles>[M]C1C(C(C)=CC=CC=CC(C)CC)Oc2ccn(OC)c(=O)c2C1O</smiles>

89: YCM1008A (2007)

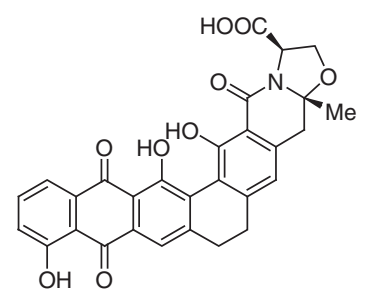

90: TMC-66 (2007)

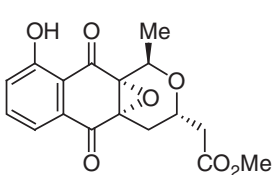

91: OM-173 $\alpha \mathrm{E}$ (2007)<smiles>C[C@H]1OC(CC(=O)O)CC23OC12C(=O)c1c(O)cccc1C3=O</smiles>

92: Nanaomycin E (2007)<smiles>COC(=O)c1cc2c3c(ccc4c3c1-c1cccc(OC)c1C4=O)[C@H](O)C(C)C2</smiles>

96: Benzopyrenomycin (2009)<smiles>CCC[C@H]1OC(C)=Cc2cc3c(c(O)c21)C(=O)C(C1OC[C@H](O)[C@H](CO)O1)=CC3=O</smiles>

100: K1115 B $B_{1 \beta}$ (2011)

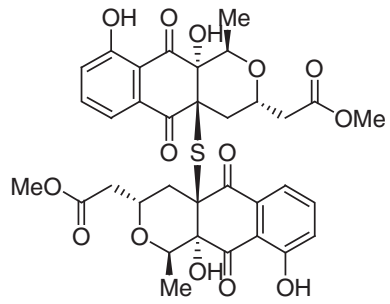

93: (+)-BE-52440A (2007)<smiles>[Y16][C@]1(O)C(Cl)=C(OC)C(=O)c2oc(=O)c3c(O)cc(OC)cc3c21</smiles>

94: (-)-TMC-264 (2008)<smiles>COC1Oc2cc(C)cc(O)c2C(=O)C2=CC=C[C@H](O)[C@@]21C</smiles>

95: Nidulalin A (2009)

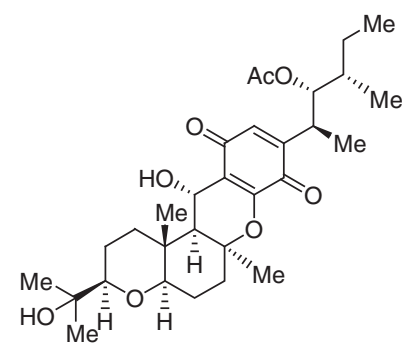

97: Epi-cochlioquinone A (2010)

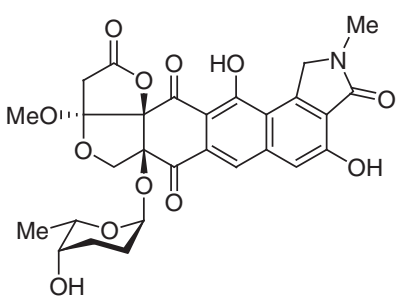

98: Lactonamycin (2010)<smiles>CCC[C@H]1OC(C)=Cc2cc3c(c(O)c21)C(=O)C(C1OCC(O)C(CO)(CO)O1)=CC3=O</smiles>

99: K1115 $B_{1 \alpha}$ (2011)<smiles></smiles>

101: XR774

(2011)

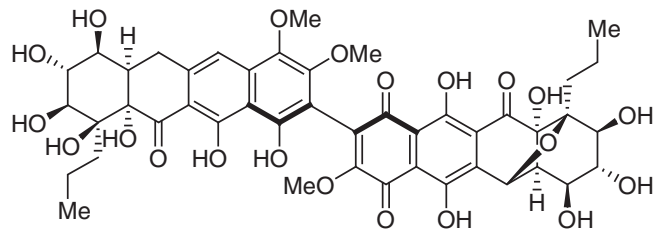

102: Hibarimicinone

(2012) 
List of 102 synthesized compounds

\begin{tabular}{|c|c|c|c|c|c|c|c|c|}
\hline No & $\begin{array}{c}\text { The first total } \\
\text { synthesis }\end{array}$ & $\begin{array}{c}\text { The big four antibiotics } \\
\text { (aminoglycoside, } \\
\text { beta-lactam, macrolide } \\
\text { and tetracycline antibiotics) }\end{array}$ & Compounds & Year & Journal title & Volume no. & Issue no. & Page range \\
\hline 1 & 0 & 0 & Neamine & 1967 & J. Antibiot. & 20 & 1 & $53-54$ \\
\hline 2 & O & 0 & Trehalosamine & 1967 & J. Antibiot. & 20 & 6 & $388-389$ \\
\hline 3 & O & O & Kanamycin A & 1968 & J. Antibiot. & 21 & 5 & $367-388$ \\
\hline 4 & $\bigcirc$ & O & Kanamycin B & 1968 & J. Antibiot. & 21 & 6 & $424-425$ \\
\hline 5 & O & 0 & Kanamycin C & 1968 & J. Antibiot. & 21 & 2 & $162-163$ \\
\hline 6 & 0 & & Chymostatin A: X=L-Leu & 1973 & J. Antibiot. & 26 & 11 & $625-646$ \\
\hline 7 & O & & Chymostatin B: $\mathrm{X}=\mathrm{L}-\mathrm{Val}$ & 1973 & J. Antibiot. & 26 & 11 & $625-646$ \\
\hline 8 & O & & Chymostatin C: $\mathrm{X}=\mathrm{L}-\mathrm{Ile}$ & 1973 & J. Antibiot. & 26 & 11 & $625-646$ \\
\hline 9 & O & O & Carbomycin B & 1977 & J. Am. Chem. Soc. & 99 & 17 & $5826-5827$ \\
\hline 10 & & & Hirsutene & 1979 & J. Am. Chem. Soc. & 101 & 20 & $6116-6118$ \\
\hline 11 & O & O & Leucomycin A3 & 1980 & Tetrahedron Lett. & 21 & 29 & $2837-2840$ \\
\hline 12 & O & & Coriolin & 1980 & J. Antibiot. & 33 & 1 & 100-102 \\
\hline 13 & 0 & & A26771B & 1980 & Tetrahedron Lett. & 21 & 15 & $1479-1482$ \\
\hline \multirow[t]{3}{*}{14} & ○ & ○ & Erythromycin A & 1981 & J. Am. Chem. Soc. & 103 & 11 & $3210-3213$ \\
\hline & & & & 1981 & J. Am. Chem. Soc. & 103 & 11 & $3213-3215$ \\
\hline & & & & 1981 & J. Am. Chem. Soc. & 103 & 11 & $3215-3217$ \\
\hline 15 & O & O & Tylosin & 1981 & Tetrahedron Lett. & 23 & 33 & $3375-3378$ \\
\hline 16 & O & & Isoretronecanol & 1982 & J. Am. Chem. Soc. & 105 & 12 & 4096 \\
\hline 17 & O & & Rosmarinecine & 1982 & J. Am. Chem. Soc. & 105 & 12 & 4096 \\
\hline 18 & O & 0 & Apramycin & 1983 & Tetrahedron Lett. & 24 & 44 & $4868-4870$ \\
\hline 19 & O & 0 & Saccharocin & 1983 & Tetrahedron Lett. & 24 & 44 & $4868-4870$ \\
\hline 20 & O & & Arphamenine & 1983 & J. Antibiot. & 36 & 12 & $1787-1788$ \\
\hline 21 & ○ & & Epi-arphamenine & 1983 & J. Antibiot. & 36 & 12 & $1787-1788$ \\
\hline 22 & 0 & & Nanaomycin D & 1985 & J. Antibiot. & 38 & 5 & $680-682$ \\
\hline 23 & 0 & & Kalafungin & 1985 & J. Antibiot. & 38 & 5 & $680-682$ \\
\hline 24 & O & & $(-)$-Nanaomycin A & 1985 & Bull. Chem. Soc. Jpn. & 58 & 6 & 1699-1706 \\
\hline 25 & $\bigcirc$ & O & Elaiophylin & 1986 & Tetrahedron Lett. & 27 & 39 & $4741-4744$ \\
\hline 26 & O & & Indisocin & 1987 & J. Antibiot. & 40 & 8 & $1202-1203$ \\
\hline 27 & O & & N-Methylindisocin & 1987 & J. Antibiot. & 40 & 8 & $1202-1203$ \\
\hline 28 & O & & Erbstatin & 1987 & J. Antibiot. & 40 & 8 & $1207-1208$ \\
\hline 29 & O & & Azepinomycin & 1987 & J. Antibiot. & 40 & 10 & $1461-1463$ \\
\hline 30 & O & O & Oleandomycin & 1988 & Tetrahedron Lett. & 29 & 32 & 3975-3978 \\
\hline 31 & O & & Pyridomycin & 1989 & Tetrahedron Lett. & 30 & 52 & $7419-7422$ \\
\hline 32 & O & ○ & Rifamycin W & 1990 & Tetrahedron & 46 & $13-14$ & $4629-4652$ \\
\hline 33 & O & & Cyclophellitol & 1990 & Tetrahedron Lett. & 31 & 8 & $1171-1172$ \\
\hline 34 & O & & Medermycin & 1990 & Tetrahedron Lett. & 31 & 38 & $5495-5498$ \\
\hline 35 & & & Allosamizoline & 1991 & Tetrahedron Lett. & 32 & 39 & $5363-5366$ \\
\hline 36 & O & 0 & Herbimycin A & 1991 & Tetrahedron Lett. & 32 & 42 & $6015-6018$ \\
\hline 37 & O & & Maniwamycin A & 1993 & Tetrahedron Lett. & 34 & 38 & $6095-6098$ \\
\hline 38 & ○ & & Maniwamycin B & 1993 & Tetrahedron Lett. & 34 & 38 & 6095-6098 \\
\hline 39 & O & & Neopyrrolomycin & 1993 & Tetrahedron Lett. & 34 & 52 & 8443-8444 \\
\hline 40 & O & & Pyrizinostatin & 1994 & J. Antibiot. & 47 & 3 & 389-390 \\
\hline 41 & 0 & & AB3217-A & 1994 & Tetrahedron Lett. & 35 & 19 & 3099-3102 \\
\hline 42 & O & & Nagstatin & 1995 & Tetrahedron Lett. & 36 & 37 & 6721-6724 \\
\hline 43 & O & & Gualamycin & 1995 & Tetrahedron Lett. & 36 & 37 & $6717-6720$ \\
\hline 44 & O & & Deacetyl-caloporoside & 1996 & Tetrahedron Lett. & 37 & 14 & $2453-2456$ \\
\hline 45 & O & & Calbistrin A & 1997 & Tetrahedron Lett. & 38 & 4 & $583-586$ \\
\hline 46 & O & & PF1092 A & 1997 & Tetrahedron Lett. & 38 & 8 & $1439-1442$ \\
\hline 47 & O & & PF1092 B & 1997 & Tetrahedron Lett. & 38 & 8 & $1439-1442$ \\
\hline 48 & O & & PF1092 C & 1997 & Tetrahedron Lett. & 38 & 8 & $1439-1442$ \\
\hline 49 & O & & MS-444 & 1997 & J. Antibiot. & 50 & 3 & 289-290 \\
\hline 50 & O & & Terpestacin & 1998 & Tetrahedron Lett. & 39 & 1 & $83-86$ \\
\hline 51 & & & KD16-U1 & 1998 & Tetrahedron Lett. & 39 & 6 & $401-402$ \\
\hline 52 & O & & Glyoxalase I inhibitor & 1998 & Tetrahedron Lett. & 39 & 6 & $401-402$ \\
\hline 53 & O & & ES-242-4 & 1998 & Tetrahedron Lett. & 39 & 13 & $1771-1772$ \\
\hline
\end{tabular}


The big four antibiotics

(aminoglycoside,

The first total beta-lactam, macrolide

\begin{tabular}{|c|c|c|c|c|c|c|c|c|}
\hline No & synthesis & and tetracycline antibiotics) & Compounds & Year & Journal title & Volume no. & Issue no. & Page range \\
\hline 54 & O & & ES-242-5 & 1999 & J. Antibiot. & 52 & 4 & $422-425$ \\
\hline 55 & O & & Sideroxylonal B & 1999 & Tetrahedron Lett. & 40 & 10 & $1925-1928$ \\
\hline 56 & O & & Sideroxylonal C & 1999 & Tetrahedron Lett. & 40 & 10 & $1925-1928$ \\
\hline 57 & ○ & & Pyralomicin 2c & 1999 & Tetrahedron Lett. & 40 & 10 & 1929-1932 \\
\hline 58 & $\bigcirc$ & & PF1163A & 1999 & J. Antibiot. & 52 & 12 & $1146-1151$ \\
\hline 59 & ○ & & PF1163B & 1999 & J. Antibiot. & 52 & 12 & $1146-1151$ \\
\hline 60 & O & & Pyralomicin 1c & 2000 & J. Antibiot. & 53 & 1 & 88-91 \\
\hline 61 & O & & PC-3 & 2000 & J. Antibiot. & 53 & 4 & $418-421$ \\
\hline 62 & ○ & & YM-30059 & 2000 & J. Antibiot. & 53 & 4 & $418-421$ \\
\hline 63 & & & Valienamine & 2000 & J. Antibiot. & 53 & 4 & $430-435$ \\
\hline 64 & & & Validamine & 2000 & J. Antibiot. & 53 & 4 & $430-435$ \\
\hline 65 & O & O & Tetracycline & 2000 & Chem. Lett. & 2000 & 6 & $646-647$ \\
\hline 66 & & 0 & Thienamycin & 2000 & J. Antibiot. & 53 & 10 & 1231-1234 \\
\hline 67 & O & & Asterriquinone B1 & 2001 & J. Antibiot. & 54 & 1 & $105-108$ \\
\hline 68 & O & & Demethylasterriquinone B1 & 2001 & J. Antibiot. & 54 & 1 & $105-108$ \\
\hline 69 & O & & Quinolactacin B & 2001 & J. Antibiot. & 54 & 1 & 109-112 \\
\hline 70 & $\bigcirc$ & & LL-Z1640-2 & 2001 & Chem. Lett. & 2001 & 2 & $172-173$ \\
\hline 71 & O & & Luminacin C1 & 2001 & Tetrahedron Lett. & 42 & 43 & $7625-7628$ \\
\hline 72 & O & & Luminacin $\mathrm{C} 2$ & 2001 & Tetrahedron Lett. & 42 & 43 & $7625-7628$ \\
\hline 73 & O & & Napyradiomycin A1 & 2002 & Chemistry Lett. & 2002 & 1 & $14-15$ \\
\hline 74 & $\bigcirc$ & O & UCE 6 & 2002 & J. Antibiot. & 55 & 12 & 1076-1080 \\
\hline 75 & O & & $\begin{array}{l}\text { 4-0-(4"-O-acetyl- } \alpha-\mathrm{L}- \\
\text { rhamnopyranosyl)-ellagic acic }\end{array}$ & 2003 & J. Nat. Prod. & 66 & 5 & 729-731 \\
\hline 76 & O & & Cochleamycin A & 2003 & J. Antibiot. & 56 & 6 & $584-590$ \\
\hline 77 & O & & Lymphostin & 2004 & Tetrahedron Lett. & 45 & 13 & $2847-2850$ \\
\hline 78 & O & & BE-5423B & 2004 & J. Antibiot. & 57 & 4 & 291-297 \\
\hline 79 & O & & Trichostatin D & 2005 & Tetrahedron Lett. & 46 & 2 & 333-337 \\
\hline 80 & 0 & & Xanthocillin X dimethyl ether & 2005 & Tetrahedron Lett. & 46 & 30 & $5017-5020$ \\
\hline 81 & O & & Xanthocillin X & 2005 & Tetrahedron Lett. & 46 & 30 & $5017-5020$ \\
\hline 82 & ○ & & YM182029 & 2005 & $\begin{array}{l}\text { Ogura, T. Doctor Thesis, } \\
\text { Waseda Univ. }\end{array}$ & & & \\
\hline 83 & 0 & & AM6898D & 2005 & $\begin{array}{l}\text { Ogura, T. Doctor Thesis, } \\
\text { Waseda Univ. }\end{array}$ & & & \\
\hline 84 & & & Tubelactomicin A & 2006 & Tetrahedron Lett. & 47 & 14 & 2439-2442 \\
\hline 85 & ○ & & Tetrodecamycin & 2006 & Tetrahedron Lett. & 47 & 21 & 3595-3598 \\
\hline 86 & ○ & & Actinopyrone A & 2006 & Tetrahedron Lett. & 47 & 30 & $5415-5418$ \\
\hline 87 & ○ & & Lagunamycin & 2006 & Tetrahedron Lett. & 47 & 35 & $6183-6186$ \\
\hline 88 & O & & Vinaxanthone & 2007 & Chemistry Lett. & 32 & 1 & 10-11 \\
\hline 89 & O & & YCM1008A & 2007 & Tetrahedron Lett. & 48 & 24 & $4187-4190$ \\
\hline 90 & 0 & & TMC-66 & 2007 & Tetrahedron Lett. & 48 & 41 & 7305-7308 \\
\hline 91 & O & & OM-173 $\alpha \mathrm{E}$ & 2007 & Tetrahedron Lett. & 48 & 45 & 8018-8021 \\
\hline 92 & O & & Nanaomycin $\mathrm{E}$ & 2007 & Tetrahedron Lett. & 48 & 45 & 8018-8021 \\
\hline 93 & O & & BE-52440 A & 2007 & Tetrahedron Lett. & 48 & 45 & 8018-8021 \\
\hline 94 & O & & TMC-264 & 2008 & Tetrahedron Lett. & 49 & 25 & 4036-4039 \\
\hline 95 & O & & Nidulalin A & 2009 & J. Antibiot. & 62 & 8 & 469-470 \\
\hline 96 & 0 & & Benzopyrenomycin & 2009 & Tetrahedron Lett. & 50 & 48 & 6701-6704 \\
\hline 97 & O & & Epi-cochlioquinone A & 2010 & Tetrahedron Lett. & 51 & 42 & $5532-5536$ \\
\hline 98 & O & & Lactonamycin & 2010 & Tetrahedron Lett. & 51 & 42 & 5546-5549 \\
\hline 99 & O & & $\mathrm{K} 1115 \mathrm{~B} 1 \alpha$ & 2011 & Tetrahedron Lett. & 52 & 9 & $983-986$ \\
\hline 100 & 0 & & $\mathrm{~K} 1115 \mathrm{~B} 1 \beta$ & 2011 & Tetrahedron Lett. & 52 & 9 & 983-986 \\
\hline 101 & O & & XR774 & 2011 & $\begin{array}{l}\text { Kataoka, Y. } \\
\text { Master Thesis, } \\
\text { Waseda Univ. }\end{array}$ & & & \\
\hline 102 & 0 & 0 & Hibarimicinone & 2012 & Tetrahedron Lett. & 53 & 4 & $422-425$ \\
\hline
\end{tabular}

